\title{
Equilibrium Search and the Impact of Equal Opportunities for Women*
}

\author{
Melvyn G. Coles \\ University of Essex \\ mcole@essex.ac.uk
}

\author{
MARCO FRANCESCONI \\ University of Essex \\ mfranc@essex.ac.uk
}

June 12, 2017

\begin{abstract}
This paper develops a new equilibrium model of two-sided search where ex-ante heterogenous individuals have general payoff functions and vectors of attributes. The analysis applies to a large class of models, from the non-transferable utility case to the collective household case with bargaining. The approach is powerful for it identifies a simple algorithm which, in the empirical application, is found to rapidly converge to equilibrium. Using indirect inference, we identify the differential effects of women's ability and charm on female match incentives. We use these results to assess the separate impacts of the arrival of equal opportunities for women in the labor market and the advent of the contraceptive pill on female economic activity and matching.
\end{abstract}

JEL Classification: C6, J0, J1, N3

Keywords: Two-sided search; Multiple attribute matching; Marriage; Female labor supply; Contraceptive pill

${ }^{*}$ We thank the Editor (James Heckman) and five anonymous referees for their very useful comments and suggestions. We are also grateful to Carlos Carrillo-Tudela, Raquel Fernandez, John Knowles, Costas Meghir, José-Víctor Ríos-Rull, and Kjetil Storesletten. The paper has also benefited from the discussions with participants at the 2013 Move Conference in Barcelona, the 2013 Family Economics Conference in Girona, and seminars at Aarhus, Essex, HSE-Moscow, and Oxford. 


\section{Introduction}

This paper develops a new equilibrium marriage model of two-sided search where exante heterogenous individuals have general payoff functions with vectors of attributes. In the existing search literature, the restriction to a single attribute is almost universal for the aggregation problem is severe: ex-ante heterogeneous singles use different match strategies and equilibrium requires that each individual's strategy must be a best response to the aggregated match strategies of the opposite sex. We provide a complete characterisation of equilibrium and an existence proof when agents have vectors of attributes. Although the paper focuses on the non-transferable utility case (in the sense of Burdett and Coles [1997]), the arguments apply equally to the collective household case (e.g., Browning and Chiappori [1998]) for which transferable utility is a special case, and allows idiosyncratic match draws as first considered in Burdett and Wright (1998). The approach is powerful for it identifies a simple algorithm which, in the numerical application, is found to rapidly converge to equilibrium. We use the framework to provide new insights on the separate impacts of equal labor market opportunities for women and improved contraceptive technologies on female education choice, labor market participation rates and marriage.

Following seminal work by Becker $(1973,1974)$, it has long been established that partnerships between men and women are positively sorted along many dimensions such as age, income, education, ethnic origin, health, height, psychometric scores (e.g., Fishman et al. 2006; Hitsch, Hortaçsu, and Ariely 2010). With frictionless matching, the existence of stable-match allocations with multiple attributes has long been established (see Browning, Chiappori, and Weiss [2014] for a useful survey). Given a restriction to finite types and transferable utility, Choo and Siow (2006) show how observed marriage patterns can be used to exactly identify the gains to marriage, while Galichon and Salanie (2010) and Dupuy and Galichon (2014) extend that approach to allow a continuum of types. ${ }^{1}$ Here instead we consider equilibrium matching with frictions where, even with modern day internet dating sites, it takes time for singles to find mutually desired life-partners. An important difference is that when rejecting a potential match, the agent's outside option here is to continue search for a preferred partner (rather than match immediately with someone else or remain permanently unmatched). The resulting framework simultaneously addresses sorting issues (who marries whom) along with the

\footnotetext{
${ }^{1}$ Chiappori, Oreffice, and Quintana-Domeque (2012) construct a model with multiple characteristics, which however reduces to matching along a one-dimensional index.
} 
timing of marriage (who marries when). ${ }^{2}$

There is a large literature on equilibrium search with ex-ante heterogeneous agents. ${ }^{3}$ By extending that framework to multiple female attributes, we analyse how the arrival of equal opportunities radically affected not only female economic activity but also partnership formation and female welfare. For following the end of World War II, the U.S. witnessed dramatic changes in the labor market. Figure 1 illustrates the post 1950s surge in female labor market participation rates, especially those of young married women with children. ${ }^{4}$ With household production increasingly sustained by new labor-saving appliances, a doubling of real wages from the mid 1930s to 1960 and with their children safely at school, women in the 1960s had an ever increasing incentive to switch more of their time to the booming labor market (Greenwood, Seshadri, and Vandenbroucke 2005; Greenwood, Seshadri, and Yorukoglu 2005). ${ }^{5}$ Greenwood et al. (2016) use a search and matching framework to argue that changes in home production technologies (the engines of liberation) were the primary factor for increased female labor market participation following the 1960s. In contrast using occupational choice data, Hsieh et al (2016) argue that college discrimination was the major factor in generating inefficient labor market outcomes. Kessler-Harris (1982, 2001) and Goldin (1990, 1991) instead describe how "marriage bars" were commonly used in professions such as doctors, lawyers, teachers and clerks, to block the employment prospects of married women. Indeed, although the Civil Rights Act became law in 1964 and so made discrimination against women illegal, it was only in 1970 that the Supreme Court finally ruled it illegal for firms to discriminate against women with children (Kessler-Harris 1982). Here we refer to the combination of technological improvements in the home (which freed women from domestic chores), the opening of university doors to women, the labor market legislative reforms (culminating in the 1963 Equal Pay Act and the 1964 Civil Rights Act) and the underlying political and cultural environment in which they were conceived (such as the Commission on the

\footnotetext{
${ }^{2}$ The only two existing equilibrium search papers with multiple attributes are by Coles and Francesconi (2011) and Lindenlaub and Postel-Vinay (2016).

${ }^{3}$ The marriage approach typically assumes non-transferable utility. See, for example, Lu and McAfee (1996), Burdett and Coles (1997, 1999), Eeckhout (1999), Bloch and Ryder (2000), Chade (2001), Chade and Ventura (2002), Smith (2006), Gautier, Svarer, and Teulings (2010), Coles and Francesconi (2011), and Díaz-Giménez and Giolito (2013). The labor market context instead assumes utility is transferable with Nash bargaining over the wage paid; see for example Shimer and Smith (2000).

${ }^{4}$ The data used to construct the figure and employed in the empirical application are described in the Appendix. We shall come back to Figure 1 in Section 3.

${ }^{5}$ Albanesi and Olivetti (2016) describe how the development of infant formula and improved medication freed the nursing mother from the home. Among the studies that emphasize a positive impact of wartime work on women's subsequent employment, see Acemoglu, Autor, and Lyle (2004), Goldin and Olivetti (2013), and Doepke, Hazan, and Maoz (2014).
} 
Status of Women, the Equal Employment Opportunity Commission, and the growth of feminism), as "the arrival of equal opportunities for women". ${ }^{6}$

In our framework male preferences over female partners depend not only on female talent and ability, but also on other characteristics such as (potential) inheritance (Stone 1977), physical beauty (Cole, Mailath, and Postlewaite 1992), pizzazz (Burdett and Coles 1997), or nurturing skills (Goldin and Katz 2002). In the application we assume women are described by a pair, ability and charm, where "ability" describes her earnings capabilities in the labor market while "charm" is assumed a non-productive asset in the labour market but is valuable in the marriage market. We further suppose the arrival of equal opportunities for women in the 1960s had a large, direct impact on the return to female ability (women now have real career options) while having relatively little impact on female charm in the marriage market. To address the impact of the introduction of the pill, we reconsider Goldin and Katz's (2002) argument that, by increasing the flow return to being single, the pill encouraged single women to delay marriage and so increased their incentive to invest in a college education.

An added contribution is we show how to identify the model using indirect inference. In the frictionless matching approach, Choo and Siow (2006) show how the fraction of individuals who marry by type can be used to identify the returns to marriage. With frictional matching, instead, the relevant metric is the hazard rate into marriage. Furthermore because unobserved heterogeneity causes the estimated hazard rate to decline with age, we show how indirect inference on estimated hazard functions by educational choice can separately identify the impacts of female charm and female ability on match outcomes and payoffs. ${ }^{7}$

An important insight is we show how a "family tax" plays a central role in explaining equilibrium match formation. Raising a two-child family is expensive: standard equivalence scales imply a family of four on joint income $Y$ enjoys the equivalent lifestyle as a single on income $0.48 Y$. From the single female's point of view then, entering a partnership to raise two children implies a direct $52 \%$ family tax on her own income (plus whatever income her partner brings to the match). This tax on own earnings implies high earning women are very selective in their search for a life-partner. In contrast,

\footnotetext{
${ }^{6}$ The change in public policies and attitudes to the employment of married women with children had a tremendous impact on female behavior, occupations, and earnings (Beller 1982; Harrison 1988; Rosen 2000). Fernandez, Fogli, and Olivetti (2004) find evidence that attitudes of men brought up in families in which the mother worked played a significant role in the increase in female labor force participation over time. See also Costa (2000) and Goldin (2006).

${ }^{7}$ Lise and Robin (2014) and Carrillo-Tudela and Visschers (2016) also use hazard functions as identifying information though in a labor market context.
} 
female charm is neither taxed in the marriage nor pays the bills while single. It does, however, attract more potential partners. With non transferable utility and search frictions, more charming women extract greater surplus from the marriage market by being suitably selective over prospective partners. ${ }^{8}$ Although in general the impact of charm on female match rates is ambiguous, indirect inference finds more charming woman, on average, match more quickly to sooner enjoy those added marital rents. Because charm and ability have very different effects on female match incentives, we show how the arrival of equal opportunities radically affected not only female economic activity but also partnership formation and female welfare.

We also consider the role that contraceptive innovations play in shaping female labor market outcomes. An influential literature has asked how the diffusion of the pill in the 1960s affected female economic activity (see for example Goldin and Katz [2002] and Bailey [2006, 2010]). As pointed out in all such studies, however, it is hard to identify separately the effect of the pill from other contemporary effects, such as the feminist movement and, more generally, the emergence of equal opportunities for women. Our argument here is that the impact of the pill on female college attendance is best considered an interaction effect: given the arrival of equal opportunities for women, how did the pill innovation additionally increase female education rates? For prior to the arrival of equal opportunities, women had no (or very little) incentive to invest in a college education. Indeed following the 1919 discovery of a new latex production technology, within 14 years the top ten U.S. condom manufacturers were producing and selling 1.44 million latex condoms per day (Tone 2001), yet this major contraceptive innovation had no significant impact on female education rates and economic activity in the 1920s.

Given equal opportunities, the calibrated model finds it is not enough to argue the pill increased female education rates by increasing the flow value of being single. If anything, results suggest that any pill which makes single life relatively more fun would seem to reduce college attendance. To argue that the pill increases college attendance, one instead has to identify mechanisms by which it subsidises the cost of education. For example one might argue that school leavers in the 1960s sought long-term partners from age 18, while college graduates could not seek long term partners until after they graduated. In that case the cost of education must also include the cost of deferred

\footnotetext{
${ }^{8}$ In contrast, with transferable utility and frictionless matching, single women extract a marital side-payment which fully compensates them for the value of their charms to men.
} 
marital search. ${ }^{9}$ By increasing the flow value of single life, the pill reduces the flow surplus to marital search which then acts as a subsidy on college attendance. Although this subsidy might be small, the calibrated model finds small subsidies on education costs have reasonably large effects on female college attendance.

The next section describes the general equilibrium marriage model of two-sided search with multiple attributes and idiosyncratic match draws for two cases: (i) non-transferable utility and (ii) the collective household model. Section 3 develops our substantive application which examines how equal opportunities in the labor market and innovations in contraception affect female economic activity and matching by type. This section also uses indirect inference to estimate parameter values and discuss many empirical results and insights. Section 4 concludes. The Appendix provides a full description of the census and survey data used in the empirical analysis.

\section{The Model}

\subsection{The Case with Non-Transferable Utility (NTU)}

We consider a continuous-time, infinite horizon family formation model with frictions and non-transferable utility. Only steady state equilibria are considered. There are two sexes, male and female (indexed by $s=m, f$ respectively) and a continuum of agents of both sexes. All partnerships involve one man and one woman and there is an equal measure of unpartnered men and women in the singles market. The parameter $\lambda>0$ denotes the rate at which any single meets a potential partner of the opposite sex. For simplicity all agents are infinitely lived, discount the future at rate $r>0$ and partnerships last forever (no divorce).

Each male is described by a vector of characteristics $\underline{x}_{m} \in \Omega_{m}$, and each female by vector $\underline{x}_{f} \in \Omega_{f}$. Should a male $\underline{x}_{m}$ match with a female $\underline{x}_{f}$, the male obtains payoff $U_{m}\left(\underline{x}_{m}, \underline{x}_{f}\right)+\theta^{m} / r$, while the female enjoys payoff $U_{f}\left(\underline{x}_{m}, \underline{x}_{f}\right)+\theta^{f} / r$. The partners' attribute-dependent payoffs $U_{m}(\cdot)$ and $U_{f}(\cdot)$ are assumed bounded for all $\left(\underline{x}_{m}, \underline{x}_{f}\right) \in\left(\Omega_{m} \times \Omega_{f}\right)$. The $\theta^{m}, \theta^{f}$ terms describe idiosyncratic "love" draws, considered as independent random draws from exogenous c.d.f. $H(\cdot)$. Note we do not rule out mass points in $H$ and so allow that $H(\cdot)$ may be degenerate. What is essential is that the surplus function $S(\widetilde{\theta})=\int_{\widetilde{\theta}}^{\infty}[1-H(\theta)] d \theta$ exists, which is a positive, continuous, decreasing function with $\lim _{\widetilde{\theta} \rightarrow \infty} S(\widetilde{\theta})=0$. The flow payoff while single is $u_{m}\left(\underline{x}_{m}\right) \geq 0$ for males and

\footnotetext{
${ }^{9}$ Of course it might be argued instead that college life offers additional dating opportunities.
} 
$u_{f}\left(\underline{x}_{f}\right) \geq 0$ for females, which are also bounded functions for all $\left(\underline{x}_{m}, \underline{x}_{f}\right) \in\left(\Omega_{m} \times \Omega_{f}\right)$.

Let $G_{m}\left(\underline{x}_{m}\right)$ describe the distribution of male attributes $\underline{x}_{m}$ across single men and $G_{f}\left(\underline{x}_{f}\right)$ the distribution of female attributes $\underline{x}_{f}$. There are search frictions and contacts are random. Should single male $\underline{x}_{m}$ meet a single woman, her attributes $\underline{x}_{f}$ are considered a random draw from $G_{f}(\cdot)$. Similarly from her perspective, his attributes $\underline{x}_{m}$ are a random draw from $G_{m}(\cdot)$. Given a contact, each observes the other's attributes and draw their independent love values $\left(\theta^{m}\right.$ or $\left.\theta^{f}\right)$. A match is formed only if both agree to it, otherwise they separate and continue search.

If two singles agree to form a match, they permanently exit the singles market and have two children, a son who inherits his father's characteristics $\underline{x}_{m}$, and a daughter who inherits her mother's characteristics $\underline{x}_{f}$. As we only consider steady states, there is no further loss in generality by assuming each child instantaneously grows up and immediately enters the singles market. Burdett and Coles (1999) refer to this as the 'clones assumption'. ${ }^{10}$ The clones assumption is convenient for it usefully abstracts from inter-cohort competition for partners: the decision to form a match and exit the pool of singles does not affect the match opportunities of the remaining singles. ${ }^{11}$ The approach is relevant for the birth cohort distribution is then endogenously determined. For example types who never marry, and so do not have children, are absent from the birth cohort. Conversely, those who match quickly are over-represented in the birth cohort (and in the general population).

\section{Strategies and Values}

Let $V^{m}\left(\underline{x}_{m}\right)$ denote the expected lifetime payoff of a single male with attributes $\underline{x}_{m}$ using an optimal matching strategy. $V^{f}\left(\underline{x}_{f}\right)$ denotes the corresponding value of a single female with characteristics $\underline{x}_{f}$. Given contact with female $\underline{x}_{f}$, a male $\underline{x}_{m}$ will propose a long term relationship if and only if his match payoff $U_{m}\left(\underline{x}_{m}, \underline{x}_{f}\right)+\theta^{m} / r$ exceeds the value of remaining single $V^{m}\left(\underline{x}_{m}\right)$. His optimal proposal strategy thus has the reservation love property: the single male will propose if and only if $\theta^{m} \geq \widetilde{\theta}^{m}$ where

$$
\widetilde{\theta}^{m}=r\left[V^{m}\left(\underline{x}_{m}\right)-U_{m}\left(\underline{x}_{m}, \underline{x}_{f}\right)\right],
$$

\footnotetext{
${ }^{10} \mathrm{An}$ alternative is to assume each child's attribute is a mix of his/her parent's characteristics plus a random element. Similarly, one might wish to endogenize the fertility choice. Both extensions are potentially important research projects, but go beyond the scope of the current paper.

${ }^{11}$ This assumption parallels that of the frictionless approach where the set of unmatched agents is exogenous.
} 
and $\widetilde{\theta}^{m}=\widetilde{\theta}^{m}\left(\underline{x}_{f} \mid \underline{x}_{m}\right)$ is type specific. We define the male proposal propensity as

$$
P^{m}\left(\underline{x}_{f} \mid \underline{x}_{m}\right)=1-H\left(\widetilde{\theta}^{m}\right),
$$

which, given a contact, is the probability male $\underline{x}_{m}$ will propose to female $\underline{x}_{f}$.

By symmetry, given contact with male $\underline{x}_{m}$, single female $\underline{x}_{f}$ has reservation love value $\widetilde{\theta}^{f}\left(\underline{x}_{m} \mid \underline{x}_{f}\right)$ given by

$$
\widetilde{\theta}^{f}=r\left[V^{f}\left(\underline{x}_{f}\right)-U_{f}\left(\underline{x}_{f}, \underline{x}_{m}\right)\right]
$$

and the female proposal propensity is then

$$
P^{f}\left(\underline{x}_{m} \mid \underline{x}_{f}\right)=1-H\left(\widetilde{\theta}^{f}\right)
$$

Given proposal propensities (1) and (2), we can now determine the set of values $V^{s}(\cdot)$ for all $\underline{x}_{s} \in \Omega_{s}, s=m, f$. Recall that at rate $\lambda$ each single male meets a potential female partner whose traits $\underline{x}_{f}$ are a random draw from $G_{f}(\cdot)$. Standard arguments imply $V^{m}\left(\underline{x}_{m}\right)$ is identified by the Bellman equation:

$$
r V^{m}\left(\underline{x}_{m}\right)=u_{m}\left(\underline{x}_{m}\right)+\lambda \int_{\underline{x}_{f} \in \Omega_{f}} \Pi^{m}\left(\underline{x}_{m}, \underline{x}_{f}\right) P^{f}\left(\underline{x}_{m} \mid \underline{x}_{f}\right) d G_{f}\left(\underline{x}_{f}\right),
$$

where

$$
\Pi^{m}\left(\underline{x}_{m}, \underline{x}_{f}\right)=\int_{-\infty}^{\infty} \max \left[U_{m}\left(\underline{x}_{m}, \underline{x}_{f}\right)+\theta^{m} / r-V^{m}\left(\underline{x}_{m}\right), 0\right] d H\left(\theta^{m}\right)
$$

In words, random matching implies $\lambda P^{f}\left(\underline{x}_{m} \mid \underline{x}_{f}\right) d G_{f}\left(\underline{x}_{f}\right)$ is the rate male $\underline{x}_{m}$ contacts a single female of type $\underline{x}_{f} \in \Omega_{f}$ who is willing to match with him. Given such a contact, he then makes expected surplus $\Pi^{m}\left(\underline{x}_{m}, \underline{x}_{f}\right)$ depending on whether his realised match payoff $U_{m}(\cdot)+\theta^{m} / r$ exceeds $V^{m}(\cdot)$. Integrating $(3)$ by parts implies $\Pi^{m}\left(\underline{x}_{m}, \underline{x}_{f}\right)=S\left(\widetilde{\theta}^{m}\right) / r$, where $\widetilde{\theta}^{m}$ is his reservation love value and $S($.$) is the surplus function. Hence V^{m}\left(\underline{x}_{m}\right)$ is the solution to the implicit function

$$
r V^{m}=u_{m}\left(\underline{x}_{m}\right)+\frac{\lambda}{r} \int_{\underline{x}_{f} \in \Omega_{f}} S\left(r\left[V^{m}-U_{m}\left(\underline{x}_{m}, \underline{x}_{f}\right)\right]\right) P^{f}\left(\underline{x}_{m} \mid \underline{x}_{f}\right) d G_{f}\left(\underline{x}_{f}\right) .
$$

Thus given $\underline{x}_{m}$ and female proposal strategies $P^{f}(\cdot) \in[0,1]$, (4) determines $V^{m}=$ $V^{m}\left(\underline{x}_{m}\right)$. The right hand side of (4) is positive at $V^{m}=0$ and the properties of the surplus 
function $S($.$) imply the right hand side is a continuous decreasing function which limits$ to $u_{m}\left(\underline{x}_{m}\right)$ as $V^{m} \rightarrow \infty$. It follows that $V^{m}\left(\underline{x}_{m}\right)$ always exists, is unique, and satisfies $V^{m}\left(\underline{x}_{m}\right) \geq u_{m}\left(\underline{x}_{m}\right) / r$. Note this argument does not imply $V_{m}($.$) is a continuous function$ for $P^{f}($.$) need not be continuous in \underline{x}_{m}$; see for example the equilibrium class structure in Burdett and Coles (1997). Fortunately continuity of $V_{m}($.$) is not necessary for the$ existence proof.

By symmetry, $V^{f}=V^{f}\left(\underline{x}_{f}\right)$ is given by

$$
r V^{f}=u_{f}\left(\underline{x}_{f}\right)+\frac{\lambda}{r} \int_{\underline{x}_{m} \in \Omega_{m}} S\left(r\left[V^{f}-U_{f}\left(\underline{x}_{f}, \underline{x}_{m}\right)\right]\right) P^{m}\left(\underline{x}_{f} \mid \underline{x}_{m}\right) d G_{m}\left(\underline{x}_{m}\right) .
$$

Equations (4) and (5) thus uniquely determine $V^{m}\left(\underline{x}_{m}\right), V^{f}\left(\underline{x}_{f}\right)$ for all $\left(\underline{x}_{m}, \underline{x}_{f}\right) \in\left(\Omega_{m} \times\right.$ $\Omega_{f}$ ) given the proposal propensities of the opposite sex. Of course equilibrium requires that these proposal propensities are consistent with the set of values $V^{m}\left(\underline{x}_{m}\right), V^{f}\left(\underline{x}_{f}\right)$.

Before defining and establishing the existence of equilibrium, it is useful first to detail how changes in proposal strategies affect agent values. Specifically, consider a woman $\underline{x}_{f}$ and two different proposal strategies by men, $P_{1}^{m}(\cdot)$ and $P_{0}^{m}(\cdot)$. Let $V_{1}^{f}\left(\underline{x}_{f}\right)$ and $V_{0}^{f}\left(\underline{x}_{f}\right)$ denote the solutions to (5) with $P^{m}$ being equal to $P_{1}^{m}$ and $P_{0}^{m}$, respectively.

Lemma 1. If $P_{1}^{m}\left(\underline{x}_{f} \mid \underline{x}_{m}\right) \geq P_{0}^{m}\left(\underline{x}_{f} \mid \underline{x}_{m}\right)$ for all $\underline{x}_{m} \in \Omega_{m}$, then $V_{1}^{f}\left(\underline{x}_{f}\right) \geq V_{0}^{f}\left(\underline{x}_{f}\right)$.

Lemma 1 simply says that a woman $\underline{x}_{f}$ is better off when all men are more likely to propose to her. The result follows immediately from (5): for any given $V^{f}$ and noting the surplus function is positive, the right hand side of this equation is increasing in $P^{m}$. Thus $V^{f}$ solving (5) must increase with an increase in $P^{m}$.

We can now identify an upper bound for values $V^{s}$. Lemma 1 implies the ideal situation for each male $\underline{x}_{m}$ is that all women propose with probability one; i.e., $P^{f}=1$ for all $\underline{x}_{f} \in \Omega_{f}$. Now consider his ideal match $\underline{x}_{f}^{*}$ defined as

$$
\underline{x}_{f}^{*}\left(\underline{x}_{m}\right)=\arg \max _{\underline{x}_{f} \in \Omega_{f}} U_{m}\left(\underline{x}_{m}, \underline{x}_{f}\right) .
$$

It follows that $V^{m}\left(\underline{x}_{m}\right) \leq \bar{V}^{m}\left(\underline{x}_{m}\right)$, where

$$
r \bar{V}^{m}=u_{m}\left(\underline{x}_{m}\right)+\frac{\lambda}{r} S\left(r\left[\bar{V}^{m}-U_{m}\left(\underline{x}_{m}, \underline{x}_{f}^{*}\right)\right]\right)
$$

for $\bar{V}^{m}$ describes the value of being single in a market where all women propose and every woman is also his ideal match. The assumptions on $S(\cdot)$ guarantee that $\bar{V}^{m}$ defined by 
(6) exists and $\bar{V}^{m} \geq u_{m}\left(\underline{x}_{m}\right) / r$. We have thus established the following result.

Lemma 2. For any male $\underline{x}_{m} \in \Omega_{m}$ and female proposal strategies $P^{f}(\cdot) \in[0,1]$, the solution for $V^{m}\left(\underline{x}_{m}\right)$ exists, is unique, and is bounded with

$$
V^{m}\left(\underline{x}_{m}\right) \in\left[\frac{u_{m}\left(\underline{x}_{m}\right)}{r}, \bar{V}^{m}\left(\underline{x}_{m}\right)\right] .
$$

Armed with Lemmas 1 and 2, we are now in a position to define and establish the existence of an equilibrium. The definition of a Matching Equilibrium simply requires the sets of values $V^{m}(\cdot)$ and $V^{f}(\cdot)$ are consistent with the proposal propensities $P^{m}$ and $P^{f}$ of the opposite sex, while those proposal propensities $P^{m}$ and $P^{f}$ are optimal given $V^{m}$ and $V^{f}$.

Definition of a Matching Equilibrium (NTU): Equilibrium is the set of functions $\left\{P^{m}, P^{f}, V^{m}, V^{f}\right\}$ over $\left(\underline{x}_{m}, \underline{x}_{f}\right) \in\left(\Omega_{m} \times \Omega_{f}\right)$ which satisfy the functional equations (1) $-(2)$ and (4)-(5).

Existence is established by considering the following fixed point. Suppose $V_{k}^{m}(\cdot)=$ $V^{m}\left(\underline{x}_{m}\right)$ for all $\underline{x}_{m} \in \Omega_{m}$ describes the equilibrium set of male values. Equation (1) then implies equilibrium male proposal propensities

$$
P_{k}^{m}\left(\underline{x}_{f} \mid \underline{x}_{m}\right)=1-H\left(r\left[V_{k}^{m}\left(\underline{x}_{m}\right)-U_{m}\left(\underline{x}_{m}, \underline{x}_{f}\right)\right]\right),
$$

for each $\underline{x}_{m} \in \Omega_{m}$. Given these male proposal propensities $P_{k}^{m}(\cdot) \in[0,1]$, the Bellman equation (5) then uniquely yields $V^{f}\left(\underline{x}_{f}\right)$ for each $\underline{x}_{f} \in \Omega_{f}$. Let $V_{k}^{f}(\cdot)$ denote this solution. Given $V^{f}=V_{k}^{f}(\cdot)$, equation (2) then yields female proposal propensities

$$
P_{k}^{f}(\cdot)=1-H\left(r\left[V_{k}^{f}\left(\underline{x}_{f}\right)-U_{f}\left(\underline{x}_{f}, \underline{x}_{m}\right)\right]\right) .
$$

Of course given these female proposal propensities $P_{k}^{f}(\cdot) \in[0,1]$, (4) then uniquely determines $V^{m}\left(\underline{x}_{m}\right)$ for all $\underline{x}_{m} \in \Omega_{m}$. Let $V_{k+1}^{m}(\cdot)$ denote this updated solution. This identifies a functional mapping $V_{k+1}^{m}\left(\underline{x}_{m}\right)=T\left[V_{k}^{m}\left(\underline{x}_{m}\right)\right]$ and equilibrium corresponds to its fixed point $V^{m}\left(\underline{x}_{m}\right)=T\left[V^{m}\left(\underline{x}_{m}\right)\right]$ for all $\underline{x}_{m} \in \Omega_{m}$. The existence proof uses the following monotonicity property.

Lemma 3. [Monotonicity] If $V_{k}^{m}\left(\underline{x}_{m}\right) \geq V_{k+1}^{m}\left(\underline{x}_{m}\right)$ for all $\underline{x}_{m} \in \Omega_{m}$, then $T\left[V_{k}^{m}\left(\underline{x}_{m}\right)\right] \geq$ $T\left[V_{k+1}^{m}\left(\underline{x}_{m}\right)\right]$ for all $\underline{x}_{m} \in \Omega_{m}$.

Proof. As $H(\cdot)$ is an increasing function, $V_{k}^{m}\left(\underline{x}_{m}\right) \geq V_{k+1}^{m}\left(\underline{x}_{m}\right)$ for all $\underline{x}_{m} \in \Omega_{m}$ and (7) implies $P_{k}^{m}(\cdot) \leq P_{k+1}^{m}(\cdot)$ for all $\underline{x}_{m} \in \Omega_{m}, \underline{x}_{f} \in \Omega_{f}$. Lemma 1 establishes $V_{k}^{f}(.) \leq V_{k+1}^{f}($. 
for all $\underline{x}_{f} \in \Omega_{f}$. As $H(\cdot)$ is an increasing function, $V_{k}^{f}(\cdot) \leq V_{k+1}^{f}(\cdot)$ for all $\underline{x}_{f} \in \Omega_{f}$ and (8) implies $P_{k}^{f}(\cdot) \geq P_{k+1}^{f}(\cdot)$ for all $\underline{x}_{f} \in \Omega_{f}, \underline{x}_{m} \in \Omega_{m}$. Lemma 1 establishes $T\left[V_{k}^{m}\left(\underline{x}_{m}\right)\right] \geq$ $T\left[V_{k+1}^{m}\left(\underline{x}_{m}\right)\right]$ for all $\underline{x}_{m} \in \Omega_{m}$ and so the map $T[\cdot]$ is monotonic.

The proof of Lemma 3 reflects the following structure. When all single men are better off, each man becomes more selective in the marriage market: given a contact with a single woman, each male proposes with a lower probability. Lemma 1 then implies every single woman is worse off for it is harder to find a male who is willing to form a permanent partnership. Now when all single women are worse off, each becomes less selective in the marriage market and their proposal propensities increase. Lemma 1 then implies every single man is better off. These feedback effects suggest multiple equilibria may occur where men, say, prefer an equilibrium in which women are less selective (and men more selective) while women prefer another equilibrium in which men are less selective (and women more selective). The proof of Lemma 3, however, shows this feedback mechanism also implies monotonicity of the map $T[V]$. Establishing existence of an equilibrium is now straightforward.

Theorem 1. A Matching Equilibrium exists.

Proof. Existence follows by repeated iteration of the map $V_{k+1}^{m}\left(\underline{x}_{m}\right)=T\left[V_{k}^{m}\left(\underline{x}_{m}\right)\right]$, starting at the upper bound $V_{0}^{m}(\cdot)=\bar{V}^{m}(\cdot)$. As $V_{1}^{m}\left(\underline{x}_{m}\right)=T\left[V_{0}^{m}\left(\underline{x}_{m}\right)\right] \leq \bar{V}^{m}\left(\underline{x}_{m}\right)$ for all $\underline{x}_{m} \in \Omega_{m}$, Lemma 3 and an induction argument imply a sequence of decreasing values $V_{k+1}^{m}\left(\underline{x}_{m}\right) \leq V_{k}^{m}\left(\underline{x}_{m}\right)$ for each $\underline{x}_{m} \in \Omega_{m}, k=0,1,2, \ldots$ As this sequence is bounded below by $u_{m}\left(\underline{x}_{m}\right) / r$, a limit point exists for every $\underline{x}_{m} \in \Omega_{m}$. As this limiting set of values is the required fixed point, an equilibrium must exist. This completes the proof of the Theorem.

The proof of Theorem 1 identifies a simple algorithm by which we can numerically compute matching equilibria. Indeed there are clear parallels with the original algorithm by Gale and Shapley (1962). That algorithm identifies stable match allocations by describing how women make acceptance decisions given the current set of male proposals, and the algorithm sequentially updates the set of male proposal choices given those acceptance rules. Here instead with search frictions, matching equilibria are identified by sequentially updating on agent values, which then determine proposal strategies. An added parallel is that if there are two equilibria where, say, all men prefer equilibrium 1 to equilibrium 2, then monotonicity of the map $T[V]$ implies iteration starting with $V_{0}^{m}(\cdot)=\bar{V}^{m}$ (i.e., men extract full marital surplus in the first step) will converge to equilibrium 1, while iteration starting with $V_{0}^{m}(\cdot)=u_{m}(\cdot) / r$ (i.e., women extract full marital surplus in the first step) will converge to equilibrium 2. 
In the next section we describe a particular application of this framework. Before doing that, however, we quickly show how this iterative algorithm also identifies equilibrium in the collective household case (e.g., Chiappori 1992; Browning and Chiappori 1998).

\subsection{Matching Equilibrium with Collective Households}

Consider a household $\left(\underline{x}_{m}, \underline{x}_{f}, \theta\right)$ which takes actions $\underline{z} \in Z$ which are jointly efficient. Because frictions imply marital surplus may be strictly positive, an equilibrium framework must describe how that surplus is shared. As is standard, we adopt the Nash bargaining approach where partners $\left(\underline{x}_{m}, \underline{x}_{f}, \theta\right)$ choose $\underline{z}$ to solve

$$
\max _{\underline{z} \in Z}\left[U^{1}\left(\underline{z} \mid \underline{x}_{m}, \underline{x}_{f}, \theta\right)-V^{m}\right]^{\alpha}\left[U^{2}\left(\underline{z} \underline{x}_{m}, \underline{x}_{f}, \theta\right)-V^{f}\right]^{1-\alpha}
$$

where $U^{1}(\cdot), U^{2}(\cdot)$ are the respective male and female payoffs within the match given actions $\underline{z}$. The threatpoints $\left(V^{m}, V^{f}\right)$ are the agents' respective values of remaining single, where $\alpha=1$ implies the male appropriates all of the match surplus while $\alpha=0$ implies the female appropriates all the match surplus. Thus $\alpha \in[0,1]$ parameterises the male share of any match surplus.

An equivalent but more convenient representation is to define the partners' "utility production possibility frontier", i.e. given any partnership $\left(\underline{x}_{m}, \underline{x}_{f}, \theta\right)$, define the Pareto frontier $U^{m}=\Upsilon\left(U^{f} \mid \underline{x}_{m}, \underline{x}_{f}, \theta\right)$, where

$$
U^{m}=\max _{\underline{z} \in Z} U^{1}\left(\underline{z} \underline{x}_{m}, \underline{x}_{f}, \theta\right) \quad \text { subject to } \quad U^{2}\left(\underline{z}_{m} \underline{x}_{m}, \underline{x}_{f}, \theta\right) \geq U^{f}
$$

If the Pareto frontier $\Upsilon\left(\cdot \underline{x}_{m}, \underline{x}_{f}, \theta\right)$ is not concave (e.g. there may be indivisibilities in the choice set $Z$ ), lotteries are then optimal (e.g. partners take turns to take out the trash), in which case we consider the convex hull of $\Upsilon\left(\cdot \mid \underline{x}_{m}, \underline{x}_{f}, \theta\right)$ which is concave. Note the transferable utility case arises when $U^{1}(\cdot), U^{2}(\cdot)$ imply $\Upsilon\left(\cdot \mid \underline{x}_{m}, \underline{x}_{f}, \theta\right)$ is linear in $U^{f}$; see Chiappori and Weiss (2007) for an example with marital public goods (children).

With this equivalent formulation in hand then, whenever a gain to trade exists, realised marital payoffs $\left(\widetilde{U}^{m}, \widetilde{U}^{f}\right)$ solve

$$
\begin{aligned}
\left(\widetilde{U}^{m}, \widetilde{U}^{f}\right) & =\arg \max _{\left(U^{m}, U^{f}\right)}\left[U^{m}-V^{m}\right]^{\alpha}\left[U^{f}-V^{f}\right]^{1-\alpha} \\
\text { subject to } U^{m} & =\Upsilon\left(U^{f} \mid \underline{x}_{m}, \underline{x}_{f}, \theta\right) .
\end{aligned}
$$


Although concavity ensures $\Upsilon(\cdot)$ is piecewise differentiable in $U^{f}$, for ease of exposition we assume it is continuously differentiable. In that case (10) implies female marital payoff $\widetilde{U}^{f}=\widetilde{U}^{f}\left(\underline{x}_{m}, \underline{x}_{f}, \theta, V^{m}, V^{f}\right)$ satisfies the first order condition

$$
\alpha \Upsilon^{\prime}\left(\widetilde{U}^{f} \mid \cdot\right)\left[\widetilde{U}^{f}-V^{f}\right]+(1-\alpha)\left[\Upsilon\left(\widetilde{U}^{f} \mid \cdot\right)-V^{m}\right]=0
$$

when $\widetilde{U}^{f} \geq V^{f}$ (otherwise there is no gain to trade and the match dissolves). Given this solution for $\widetilde{U}^{f}$, the male obtains marital payoff

$$
\widetilde{U}^{m}=\Upsilon\left(\widetilde{U}^{f} \mid \underline{x}_{m}, \underline{x}_{f}, \theta\right)
$$

Of course the threatpoints $V^{m}=V^{m}\left(\underline{x}_{m}\right), V^{f}=V^{f}\left(\underline{x}_{f}\right)$ are, in equilibrium, determined by optimal search while single. We describe equilibrium search below. Anticipating the fixed point argument, however, we first describe how marital payoffs $\left(\widetilde{U}^{m}, \widetilde{U}^{f}\right)$ vary with exogenous threatpoints $\left(V^{m}, V^{f}\right)$.

Lemma 4. Should a gain to trade exist, that is $\widetilde{U}^{f}\left(\underline{x}_{m}, \underline{x}_{f}, \theta, V^{m}, V^{f}\right)>V^{f}$, then:

(i) $0 \leq \frac{\partial \widetilde{U}^{f}}{\partial V^{f}} \leq 1$ : the female partner negotiates a higher payoff should her threat point increase, and

(ii) $\frac{\partial \widetilde{U}^{f}}{\partial V^{m}} \leq 0$ : the female partner negotiates a lower payoff should her partner's threat point increase.

The equivalent statement applies for $\widetilde{U}^{m}$.

Proof. The proof is a trivial comparative static exercise on (11), where $\Upsilon(\cdot)$ must be concave.

We can now describe a Matching Equilibrium for the Collective Households case. Consider a single male $\underline{x}_{m} \in \Omega_{m}$ and suppose in equilibrium he enjoys value $V^{m}=$ $V^{m}\left(\underline{x}_{m}\right)$ while single. If he contacts woman $\underline{x}_{f}$ with value $V^{f}=V^{f}\left(\underline{x}_{f}\right)$ and if match draw $\theta$ implies a gain to trade exists, he negotiates marital payoff $\widetilde{U}^{m}\left(\underline{x}_{m}, \underline{x}_{f}, \theta, V^{m}, V^{f}\left(\underline{x}_{f}\right)\right) \geq$ $V^{m}$ as determined by (11)-(12). Conversely if realised $\theta$ implies there is no gain to trade, the two separate and continue search. Thus given the set of equilibrium female values $V^{f}($.$) , standard arguments imply V^{m}=V^{m}\left(\underline{x}_{m}\right)$ solves the Bellman equation:

$$
r V^{m}=u_{m}\left(\underline{x}_{m}\right)+\lambda \int_{\underline{x}_{f} \in \Omega_{f}} E_{\theta}\left[\max \left[\widetilde{U}^{m}\left(\underline{x}_{m}, \underline{x}_{f}, \theta, V^{m}, V^{f}\left(\underline{x}_{f}\right)\right)-V_{m}, 0\right] d G_{f}\left(\underline{x}_{f}\right) .\right.
$$

Equation (13) is an implicit function for $V^{m}=V^{m}\left(\underline{x}_{m}\right)$. As Lemma 4 implies $\partial \widetilde{U}^{m} / \partial V^{m}$ $\leq 1$, the right hand side of (13) is positive, continuous, decreasing in $V_{m}$ and limits to 
$u_{m}\left(\underline{x}_{m}\right)$ as $V^{m} \rightarrow \infty$. Thus $V^{m}=V^{m}\left(\underline{x}_{m}\right)$ exists, is unique, and satisfies $V^{m}\left(\underline{x}_{m}\right) \geq$ $u_{m}\left(\underline{x}_{m}\right) / r$.

By symmetry, $V^{f}=V^{f}\left(\underline{x}_{f}\right)$ solves the Bellman equation

$$
r V^{f}=u_{f}\left(\underline{x}_{f}\right)+\lambda \int_{\underline{x}_{m} \in \Omega_{m}} E_{\theta} \max \left[\widetilde{U}^{f}\left(\underline{x}_{m}, \underline{x}_{f}, \theta \mid V^{m}\left(\underline{x}_{m}\right), V^{f}\right)-V^{f}, 0\right] d G_{m}\left(\underline{x}_{m}\right),
$$

which also exists, is unique, and satisfies $V^{f}\left(\underline{x}_{m}\right) \geq u_{f}\left(\underline{x}_{f}\right) / r$.

We maintain the assumption that all couples have two children who are identical to the parents. The birth cohort is thus endogenously determined while the distributions of singles $G_{m}$ and $G_{f}$ are independent of agent match strategies.

Definition of a Matching Equilibrium (Collective Households): Equilibrium is the set of marital payoffs and values $\left\{\widetilde{U}^{m}, \widetilde{U}^{f}, V^{m}, V^{f}\right\}$ for all $\left(\underline{x}_{m}, \underline{x}_{f}\right) \in\left(\Omega_{m} \times \Omega_{f}\right)$ such that:

(i) whenever a gain to trade exists, $\left\{\widetilde{U}^{m}, \widetilde{U}^{f}\right\}$ satisfy $(11),(12)$ with $V^{m}=V^{m}\left(\underline{x}_{m}\right)$, $V^{f}=V^{f}\left(\underline{x}_{f}\right)$, and

(ii) $V^{m}=V^{m}\left(\underline{x}_{m}\right), V^{f}=V^{f}\left(\underline{x}_{f}\right)$ satisfy the functional equations (13)-(14) with $\left\{\widetilde{U}^{m}, \widetilde{U}^{f}\right\}$ given by (i).

Because the same fixed point argument applies, we quickly sketch the relevant details. As before let $V_{k}^{m}(\cdot)=V^{m}\left(\underline{x}_{m}\right)$ for all $\underline{x}_{m} \in \Omega_{m}$ describe the equilibrium set of male values. With $V^{m}(\cdot)=V_{k}^{m}(\cdot)$, (10) and (14) determine $V^{f}\left(\underline{x}_{f}\right)$ for each $\underline{x}_{f} \in \Omega_{f}$ and the above has established a solution exists, is unique with $V^{f}\left(\underline{x}_{m}\right) \geq u_{f}\left(\underline{x}_{f}\right) / r$. Let $V_{k}^{f}(\cdot)$ denote this set of values. With $V^{f}(\cdot)=V_{k}^{f}(\cdot)$, (10) and (13) now uniquely determine $V^{m}\left(\underline{x}_{m}\right)$ for each $\underline{x}_{m} \in \Omega_{m}$. Let $V_{k+1}^{m}(\cdot)$ denote the updated set of values. This identifies a functional map $V_{k+1}^{m}(\cdot)=T\left[V_{k}^{m}(\cdot)\right]$, where its fixed point $V^{m}(\cdot)=T\left[V^{m}(\cdot)\right]$ describes the matching equilibrium.

The same argument establishes monotonicity of the map $T\left[V^{m}(\cdot)\right]$. Consider any two sets of male values $V^{m}\left(\underline{x}_{m}\right)$ for $\underline{x}_{m} \in \Omega_{m}$, denoted $V_{k}^{m}(\cdot)$ and $V_{k+1}^{m}(\cdot)$ where $V_{k}^{m}\left(\underline{x}_{m}\right) \geq$ $V_{k+1}^{m}\left(\underline{x}_{m}\right)$ for all $\underline{x}_{m} \in \Omega_{m}$. Consider any female $\underline{x}_{f} \in \Omega_{f}$ and note Lemma 4 implies $\partial \widetilde{U}^{f} / \partial V^{m} \leq 0$, i.e. a female negotiates a lower payoff the greater her partner's threatpoint. It is then immediate that if all men have higher values $V_{k}^{m}(\cdot) \geq V_{k+1}^{m}(\cdot)$, the corresponding fall in $\widetilde{U}^{f}$ in (14) implies $V^{f}$ must be lower; that is $V_{k}^{f}\left(\underline{x}_{f}\right) \leq V_{k+1}^{f}\left(\underline{x}_{f}\right)$ for all $\underline{x}_{f} \in \Omega_{f}$. By symmetry it then follows that if all women have lower threatpoints $V_{k}^{f}\left(\underline{x}_{f}\right) \leq V_{k+1}^{f}\left(\underline{x}_{f}\right)$ for all $\underline{x}_{f} \in \Omega_{f}$, then each male negotiates a higher payoff $\widetilde{U}^{m}$ in 
any match. Thus we have $T\left[V_{k}^{m}\left(\underline{x}_{m}\right)\right] \geq T\left[V_{k+1}^{m}\left(\underline{x}_{m}\right)\right]$ for all $\underline{x}_{m} \in \Omega_{m}$ and so $T($.$) is$ monotonic.

Establishing existence requires ensuring payoffs are bounded. The lower bound for female payoffs is $u_{f}\left(\underline{x}_{f}\right) / r$ for women can always choose not to marry. Putting $V^{f}=$ $u_{f}\left(\underline{x}_{f}\right) / r$ now implies the upper bound of male values, denoted $\bar{V}^{m}\left(\underline{x}_{m}\right)$, is the solution to the Bellman equation

$$
r \bar{V}^{m}=u_{m}\left(\underline{x}_{m}\right)+\lambda \int_{\underline{x}_{f} \in \Omega_{f}} E_{\theta} \max \left[\widetilde{U}^{m}\left(\underline{x}_{m}, \underline{x}_{f}, \theta \mid \bar{V}^{m}, u_{f}\left(\underline{x}_{f}\right) / r\right)-\bar{V}_{m}, 0\right] d G_{f}\left(\underline{x}_{f}\right) .
$$

Because Lemma 4 establishes $\left[\widetilde{U}^{m}()-.\bar{V}_{m}\right]$ is decreasing in $\bar{V}^{m}$ for $\bar{V}^{m} \geq u_{m}\left(\underline{x}_{m}\right) / r$, it follows that assuming $E_{\theta}\left[\widetilde{U}^{m}\left(\underline{x}_{m}, \underline{x}_{f}, \theta \mid u_{m}\left(\underline{x}_{m}\right) / r, u_{f}\left(\underline{x}_{f}\right) / r\right)\right]$ is uniformly bounded for all $\left(\underline{x}_{m}, \underline{x}_{f}\right) \in \Omega_{m} \times \Omega_{f}$ is sufficient to ensure this upper bound $\bar{V}^{m}$ exists. As this also implies $\bar{V}^{m}\left(\underline{x}_{m}\right) \geq u_{m}\left(\underline{x}_{m}\right) / r$, then setting $V_{0}^{m}(\cdot)=\bar{V}^{m}(\cdot)$ and iterating, the map $V_{k+1}^{m}(\cdot)=T\left[V_{k}^{m}(\cdot)\right]$ yields a decreasing sequence of functions $V_{k}^{m}(\cdot)$. Since this sequence of functions is bounded below by $u_{m}\left(\underline{x}_{m}\right) / r$, the limiting function must exist and identifies a Matching Equilibrium.

\section{Application: Equal Opportunities and the Pill}

Because the data used contains no information on household choices, we adopt the NTU approach. To focus on female behavior, we keep the male side of the market deliberately simple. Each male is characterized by a scalar, $\underline{x}_{m} \equiv y$, which describes his labor market earnings. Earnings across single men have distribution $G^{m}(\cdot)$ and support $[\underline{y}, \bar{y}]$. We instead suppose women have two attributes $(n, \alpha)$, where $n$ describes her innate charm to men and $\alpha$ is an ability variable that describes her potential earnings in the labor market.

This heterogeneity structure allows us to consider how marital incentives and outcomes changed across the arrival of equal opportunities for women. Prior to the arrival of equal opportunities, we presume married women with children had highly restricted labor market opportunities. This has important implications for the marriage market since single men then put greater emphasis on seeking more charming partners, rather than high ability ones. The second scenario instead supposes the arrival of equal opportunities allows more able (high $\alpha$ ) women to earn higher wages in the labour market. This not only changes the (ex-post) labor market opportunities of women with children, and thus the ex-ante education choices of young women, it also changes the timing and 
structure of partnership formation. In this way we address how the advent of equal opportunities not only affected female economic activity but also marital outcomes.

We also follow Goldin and Katz (2002) and consider the impact of the pill on education choice by assuming that the pill increased the flow payoff of being single relative to the flow payoff of being married. Using a two period model, Goldin and Katz (2002) argue that by reducing the cost to delaying marriage, the pill increased the return to female education. Our extended framework allows a richer analysis.

\subsection{Model}

Let $\widetilde{G}^{f}(\cdot)$ denote the ex-ante distribution of attributes $(n, \alpha)$ across single women. Prior to entering the marriage market, each woman $(n, \alpha)$ makes an education choice $e \in\{0,1\}$ with $e=1$ indicating university education and $e=0$ otherwise. For convenience we refer to those who choose $e=1$ as college educated, those with $e=0$ are college uneducated. The cost of education $c>0$ is the same for all.

Given her education choice $e$ and attributes $(n, \alpha)$, her wage $w$ earned in the labor market is: (i) $w=\underline{y}$ if there are unequal labor market opportunities, (ii) $w=\alpha$ if there are equal opportunities and $e=0$ (uneducated), (iii) $w=\gamma \alpha$ if there are equal opportunities and $e=1$ (educated), where $\gamma>1$ describes the wage return to education. Given the sunk education choice, each woman in the marriage market is then described by expost characteristics $(n, w)$. Hence given the ex-ante distribution of female characteristics $\widetilde{G}^{f}(n, \alpha)$, the education choices of women yield $G^{f}(n, w)$ defined as the distribution of ex-post female attributes $(n, w)$ in the marriage market.

Family consumption is assumed to be a joint public good and labor supply is jointly efficient. A match between male $y$ and female $(n, w)$ yields the following lifetime payoffs:

$$
U^{m}=\frac{\beta[y+\max [w-\phi, 0]]+n+F}{r} ; \quad U^{f}=\frac{\beta[y+\max [w-\phi, 0]]+F}{r},
$$

where $\beta, \phi$, and $F$ are positive parameters. The male's flow payoff in the match depends on joint labor market earnings $y+\max [w-\phi, 0]$ where $\phi$ describes the opportunity cost of child care, i.e., the female partner continues in the labor market if her earnings $w \geq \phi$. We assume $\phi>\underline{y}$, so that a married woman who only earns $\underline{y}$ will not participate in the labor market and so becomes a "homemaker". Conversely, a high earning woman with $w>\phi$ will participate and purchase child services at cost $\phi .{ }^{12}$ Joint earnings are deflated

\footnotetext{
${ }^{12}$ An alternative specification, as considered in Coles and Francesconi (2011), is that the higher earner participates in the labor market, while the lower earner only works if the added earnings compensate
} 
by $\beta \in(0,1]$. Given a family size of two adults and two children, the case $\beta=1$ assumes "four can live as cheaply as one". $\beta<1$ instead acts as a "family tax": the single man who enjoys flow earnings $y$ only enjoys consumption flow value $\beta y$ when married with children, though with an additional income boost of $\beta \max [w-\phi, 0]$ depending on his partner's earnings. $F$ describes the additional flow utility enjoyed by marrying and raising a family. ${ }^{13}$

The female match payoff $U^{f}(\cdot)$ has an identical structure, the only difference being that her match payoff does not depend directly on her own charm $n$. An interesting motivation for this preference structure is that males might value future daughter happiness. Because daughter happiness will depend on her own charm, the clones assumption implies males seek more charming wives. In contrast, the clones assumption instead implies a charming woman automatically raises a charming daughter. For her the additional value of her charms is that she can attract a more desirable male $y$, and her son will then also be a high $y$. For simplicity we do not consider such intergenerational payoffs. ${ }^{14}$

The flow payoff of a single male is $u_{m}(y)=y+u$, whereas the flow payoff to a single woman is $u_{f}(n, w)=w+u$ which depends on their earnings while single. Following Goldin and Katz (2002), we assume improved contraception raises $u$, the flow value of being single relative to the flow value of marriage; that is, improved contraception reduces the cost to delaying partnership formation.

\section{Matching Equilibria with Unequal Opportunities}

According to this structure, prior to the arrival of equal opportunities a woman can only earn wage $\underline{y}$ in the labor market which might be considered an extreme version of the "marriage bar". As child care costs $\phi>\underline{y}$, each married woman with children withdraws from the labor market to become a homemaker and match payoffs (15) simplify to

$$
U^{m}=\frac{\beta y+n+F}{r} ; \quad U^{f}=\frac{\beta y+F}{r} .
$$

Because these payoffs do not depend on female ability $\alpha$, men value potential female partners purely by charm $n$. Because this structure implies a zero female return to for child care costs.

${ }^{13}$ Allowing $F$ to be gender specific and idiosyncratic is potentially important, but this is an extension left to future research.

${ }^{14}$ For a model with intergenerational payoffs, see Cole, Mailath, and Postlewaite (1992) on the value of aristocracy, an inherited asset with no intrinsic value but which can be prized in a matching equilibrium. 
education, young women do not invest in a costly college education.

Let $V^{m}(y)$ denote the value of a single male with income $y$ and $V^{f}(n)$ denote the value of a single female with charm $n$. The analysis for the general case now applies. Given contact with female $n$, a single male $y$ has $\widetilde{\theta}^{m}=r V^{m}(y)-\beta y-n-F$ and thus proposal propensity

$$
P^{m}(n \mid y)=1-H\left(r V^{m}(y)-\beta y-n-F\right) .
$$

Similarly, given contact with male $y$, a single female $n$ has reservation love value $\widetilde{\theta}^{f}=$ $r V^{f}(n)-\beta y-F$ and corresponding proposal propensity

$$
P^{f}(y \mid n)=1-H\left(r V^{f}(n)-\beta y-F\right) .
$$

Given (18), the single male $y$ enjoys value $V^{m}=V^{m}(y)$ satisfying

$$
r V^{m}=u+y+\frac{\lambda}{r} \int_{\underline{n}}^{\bar{n}} S\left(r V^{m}-\beta y-n-F\right) P^{f}(y \mid n) d G^{f}(n),
$$

where $G^{f}(n)$ describes the distribution of charm across single women. Likewise, the single female $n$ enjoys value $V^{f}=V^{f}(n)$ satisfying

$$
r V^{f}=u+\underline{y}+\frac{\lambda}{r} \int_{\underline{y}}^{\bar{y}} S\left(r V^{f}-\beta y-F\right) P^{m}(n \mid y) d G^{m}(y) .
$$

A Matching Equilibrium is the set of functions $\left\{P^{m}, P^{f}, V^{m}, V^{f}\right\}$ satisfying the functional equations (17)-(20). Theorem 1 establishes a Matching Equilibrium exists.

\section{Matching Equilibria with Equal Opportunities}

With the arrival of equal opportunities, the payoff structure (15) implies female investment in education generates two benefits. First, it yields a better standard of living, both while single and when married (if $w>\phi$ ). Second, it affects her marital options. To separate out these two effects, it is useful to define female "fitness" $z$ as $z=n+\beta \max [w-\phi, 0]$ for then the male and female match payoffs can be written as

$$
U^{m}=\frac{\beta y+z+F}{r} ; \quad U^{f}=\frac{\beta y+\beta \max [w-\phi, 0]+F}{r} .
$$

Because men rank women according to fitness $z$, rather than charm $n$, it is convenient 
to relabel each female $(n, w)$ by her equivalent characteristics $(z, w)$.

Given the distribution of male earnings $G^{m}(y)$ and ex-post female characteristics $G^{f}(z, w)$, it is easy to formulate the value function for each sex, obtain the corresponding proposal propensities and use Theorem 1 to establish existence of a Matching Equilibrium. Of course we must in addition describe an investment equilibrium where, given the matching equilibrium, each female $(n, \alpha)$ makes a privately optimal education choice which endogenously maps female characteristics $(n, \alpha)$ to ex-post attributes $(z, w)$. As detailed in Burdett and Coles (2001), these investment incentives are not efficient because women who invest in education ignore that by becoming more selective in the singles market they make some single men worse off. There is also a standard hold-up problem.

\subsection{Indirect Inference}

\section{Maintained Baseline Parameters and Distributional Assumptions}

Table 1 describes the baseline parameter values and functional forms. All have a standard annual discount rate of $r=4 \%$. Because $(F-u)$ describes the net increase in flow utility through starting a family, we can normalize $u=0$. Childcare costs, $\phi$, are set at $\$ 10,732$ per year for two children. This figure comes from the estimate of child care expenditures of $19.9 \%$ of female yearly personal income per child by Macartney and Laughlin (2011; Table 2). With an average personal labor income of $\$ 26,964$ from the 2000 Census ( $\$ 21,750$ for the $75 \%$ low education women and $\$ 41,350$ for the $25 \%$ college educated women), this estimate leads to annual child care costs of $\$ 5,366$ per child (or $\$ 10,732$ for two children, as assumed in the model).

The distribution of male earnings $G_{m}(y)$ is (truncated) log normal. The 2000 Census data on male earnings yields a mean of 10.44 and a standard deviation of 0.687 . We truncate at two standard deviations from the mean, so that $\underline{y}=\$ 9,608$ and $\bar{y}=\$ 157,192$ per annum, and renormalize the probability weights accordingly. $G_{f}(\alpha)$ is also truncated log normal distribution where we assume that women have the same distribution of abilities as men, but deflated by parameter $\gamma>1$. Thus if all women invest in education, equal opportunities implies women enjoy the same distribution of wages.

Education cost $c$ is set at $\$ 57,069$. This includes both the tuition fee of attending a four-year program in a public university and foregone labor income while attending college. The National Center for Education Statistics states the average annual cost for undergraduate tuition and fees in public institutions offering a four-year degree between 
2000 and 2003 was $\$ 3,967$ (ranging between $\$ 3,501$ and $\$ 4,587$ ). The total average cost over the four-year period is therefore $\$ 15,869$. The foregone earnings are estimated as the Federal Minimum Wage (\$5.15 per hour in 2000) multiplied by 2000 hours of fulltime work per year. This yields estimate $\$ 10,300$ per year, or $\$ 41,200$ over a four-year period. ${ }^{15}$ The figure in Table 1 is thus the sum of the direct cost $(\$ 15,869)$ and the opportunity cost $(\$ 41,200)$.

The distribution of female charm is assumed to be orthogonal to the distribution of female abilities. ${ }^{16}$ As there is no objective information on the distribution of charm $n$ in the population (Buss 2003), we suppose there are just two levels $n \in\{-\bar{n}, \bar{n}\}$, which is symmetrically distributed and so $\bar{n}$ also describes the standard deviation of charm across single women. We use $\mathcal{L}$ to label women with charm $n=-\bar{n}<0$, and $\mathcal{H}$ to label those with charm $n=\bar{n}>0$.

The distribution of idiosyncratic (match specific) draws, $H(\cdot)$, is assumed to be $N\left(\mu, \sigma^{2}\right)$. Again, noting that $(F-u-\mu)$ describes the expected net increase in flow utility through starting a family, we normalise $\mu=0$.

The official income equivalence scale for a married couple with two children is 2.1 (Organisation for Economic Co-operation and Development 2008): that is, a couple raising two children on joint income $2.1 Y$ enjoy the same consumption lifestyle as a single on income $Y$. In our model specification this is equivalent to setting $\beta=0.48$. As a robustness check, we have also allowed the calibration to choose $\beta$ as a free parameter. Doing this yields estimated $\beta=0.51$. This parameter plays a major role in determining equilibrium match formation for we find a small change in $\beta$ has a significant impact on the quality of fit. We therefore describe the calibration results with $\beta$ at its optimised value of 0.51 rather than the OECD suggested figure of 0.48 . The results, however, are qualitatively identical.

\section{Targets and Identification}

The remaining model parameters $(\lambda, F, \sigma, \bar{n}, \gamma)$ are chosen so that the model outcomes are consistent with a number of empirical moments. The first target moment is the fraction of all women aged 25-34 in the 2000 Census who have a university qualification, which is equal to $25.5 \%$. This target moment ties down the return to education, $\gamma$.

\footnotetext{
${ }^{15}$ An alternative measure of the opportunity cost comes from the 2000 U.S. Census, according to which the mean earnings of female high-school (including GED) graduates aged 18-21 are $\$ 9,042$, which become $\$ 36,168$ over four years. Using this alternative measure does alter our results.

${ }^{16}$ Although Hamermesh and Biddle (1994) find evidence of a positive impact of workers' physical looks on their earnings, we simplify by abstracting from this effect.
} 
The second target moment ensures the model outcome is consistent with observed marital sorting. Fernandez, Guner, and Knowles (2005) use the correlation between spouses' years of schooling to identify marital sorting. Across 34 countries, they find this correlation ranges between 0.32 (Australia) and 0.76 (Colombia), with an average of 0.60. ${ }^{17}$ For post-marital earnings, Jacquemet and Robin (2012) report a correlation between spousal wages of 0.30 using data from the Survey of Income and Program Participation, while Hess (2004) reports a correlation of 0.22 using data from the National Longitudinal Survey of Youth. Here we instead target the correlation of pre-marital incomes across matched partners. Using data from the Panel Study of Income Dynamics and the British Household Panel Survey, the estimated correlation between partner premarital wages $(y, w)$ range between 0.45 and 0.53 . We thus set a target equal to 0.5. This target ties down the calibrated value of $\sigma$, the standard deviation of match draws, for a larger $\sigma$ implies that types seek more their idiosyncratic "true loves" which reduces sorting by earnings.

The third set of target moments uses the estimated female hazard rates into first partnership by age and education where, to reflect recent trends, we use entry into first partnership rather than entry into first marriage as our measure of the timing of partnership formation. This is useful identifying information for two reasons. First, the average rate of entry into first partnership across education categories ties down the calibrated values for $\lambda$ and $F$. Second, unobserved heterogeneity leads to decreasing hazard functions, where the rate at which the hazard function decreases with age depends on the dispersion in underlying female attributes. Furthermore, because it is the higher ability women who invest in education, we show how the difference in the levels and slopes of the estimated hazard functions (by education category) identifies the separate impact and relative importance of ability $\alpha$ and charm $n$ on female match outcomes.

Using standard life table analysis (Kalbfleisch and Prentice 2002), we estimate female hazard rates into first partnership by age and education category using the 2002-2003 NSFG data. Figure 2 plots the results. Not surprisingly, the hazard function for highschool dropouts peaks at an earlier age (23 years) relative to the peak age for college educated women (25 years). These peaks correspond well to first birth activity: conditional on having at least one child, the average age at first birth is 23.3 years for low educated women and 28.4 years for college graduates. To mitigate non-stationarity

\footnotetext{
${ }^{17}$ Using census data, Greenwood et al. (2016) report a correlation coefficient between husband's and wife's education levels that goes from 0.41 in 1960 to 0.52 in 2005.
} 
problems due to declining female fertility by age, we do not consider empirical hazard functions beyond age 30 .

In a labor market context, Lise and Robin (2014) and Carrillo-Tudela and Visschers (2016) also use indirect inference on hazard functions to identify unobserved heterogeneity. In a marriage market context, however, there is an additional identification issue: we have no information regarding when a single woman begins to seek a long term partner. For example, Figure 2 reveals that some low-educated women at age 18 enter a long term relationship, which is clearly not the case for women who invest in education. The obvious interpretation is that college students delay search for permanent partners until after they complete their studies, e.g. Goldin and Katz (2002) and Lundberg and Pollak (2013). As the model can only be consistent with decreasing hazard functions, however, we operationalise the approach by using as target moments the estimated hazard functions following their peak values (see Table 2). In other words, we assume uneducated women begin to seek long-term partners at age 23 , two years before educated women. A key feature of these targets, then, is that the hazard rates into first partnership by loweducated women are initially higher but fall more quickly with duration on the singles market.

The calibration thus chooses parameters $(\lambda, F, \sigma, \bar{n}, \gamma)$ to minimise the following weighted loss function

$$
L(\lambda, F, \sigma, \bar{n}, \gamma)=\left[\frac{\widehat{\pi}-0.255}{0.255}\right]^{2}+\left[\frac{\widehat{\rho}-0.5}{0.5}\right]^{2}+\sum_{e=0}^{1} \sum_{a=1}^{5}\left[\frac{\widehat{h^{e}}(a)-h^{e}(a)}{h^{e}(a)}\right]^{2}
$$

where $\widehat{\pi}$ is the model predicted equilibrium fraction of women who invest in education, $\widehat{\rho}$ is the model predicted equilibrium correlation of pre-marital incomes across matched partners, and $\widehat{h^{e}}(a)$ is the model predicted average hazard rate into first partnership by women in education category $e=\{0,1\}$, given duration $a$ on the singles market, computed as

$$
\widehat{h^{e}}(a)=\frac{\sum_{i} \mu_{i}^{e} e^{-h_{i} a} h_{i}}{\sum_{i} \mu_{i}^{e} e^{-h_{i} a}}
$$

where $\mu_{i}^{e}$ is the number (measure) of single females of type $i$ who choose education $e=\{0,1\}$, and $h_{i}$ is their equilibrium hazard rate into partnership.

Results 
Table 3 reports our inferred parameter values. Estimated $\lambda$ implies a contact rate of 8 potential partners a year, a rate which is reasonable once it is understood that most such contacts are unsuitable and quickly terminated. The inference is that hazard rates into first partnership are low not because frictions are inordinately high, but rather because singles are highly selective and a match requires a double coincidence of wants.

Because the family tax $1-\beta$ is large, the imputed return to raising a family, $F=$ $\$ 31,000$ per annum, is large to compensate. The estimated return to education, $4.7 \%$, precisely yields the target female education rate of $25.5 \%$. This latter estimate is very close to the average returns to education found in all the twins studies reviewed by Card (1999). ${ }^{18}$

The estimated standard deviation of love draws, $\sigma=\$ 8,300$ per year, precisely yields the target for sorting by pre-marital wages. Although the estimated $\sigma$ is non-zero and so idiosyncratic match draws play a role, $\sigma$ is much smaller than the estimated standard deviation of female charm $\bar{n}=\$ 25,900$. This inference arises because the target hazard function for uneducated women $(e=0)$ is steeply declining with duration, where large idiosyncratic match draws, and thus more random matching, would instead yield a flat hazard function. The resulting interpretation is that male match preferences are much more affected by female charm than by idiosyncratic love draws.

The target hazard function for educated women $(e=1)$ is instead comparatively flat. So why for educated women would charm seem to play a less important role? Figure 3 describes the (model) female hazard rates $h_{j}(\alpha)$ decomposed by ability $\alpha$ and charm $j=\mathcal{L}, \mathcal{H}$. On the figure we also mark the ability thresholds, $\alpha_{\mathcal{L}}, \alpha_{\mathcal{H}}$, where women with charm $j=\mathcal{L}, \mathcal{H}$ invest in education if and only if their ability $\alpha \geq \alpha_{j}$. This figure reveals that dispersion in charm leads to much wider dispersion in match rates across uneducated (sufficiently low ability) women than across educated women, and it is this feature of the model which generates a steep hazard function for types $e=0$ and a flat one for types $e=1$. But why does this arise?

Charm and ability generate very different match incentives for single women, and an interaction effect finds charm is much less valuable to higher ability women. Note this cannot occur in a frictionless stable matching environment with transferable utility, because there women receive a transfer payment from men which fully compensates the value of their charm $n$. But in an NTU framework with search frictions, a more

\footnotetext{
${ }^{18}$ This is also in line with the estimates reported in discrete choice dynamic programming models, such as Eckstein and Wolpin (1989).
} 
charming woman can only extract greater surplus from the marriage market by being suitably selective over potential partners. As charm does not pay the bills while single, the more charming woman has the incentive to match relatively quickly: by attracting more male proposals, the calibrated model finds $\mathcal{H}$-type women unambiguously match more quickly at every ability level. A single woman on a higher wage also finds her higher fitness attracts more male proposals, but she in addition enjoys a higher quality lifestyle while single and faces "family tax" $(1-\beta) w$ to forming a partnership. In general, the impact of higher $w$ on female match rates is ambiguous. ${ }^{19}$ The critical property of the calibrated model is that the impact of charm on the match rates of high ability women is small: high earning single women find the added value of charm (which attracts more potential partners) is of relatively little consequence given they are already highly selective over potential male partners. We discuss further the value of charm below. But because charm has lower impact on female match rates for types $e=1$, the resulting $e=1$ hazard function is comparatively flat.

Table 2 reports the target hazard functions by education $e$ and normalised age (duration on the singles market) and the fitted hazard function using model generated data. The calibrated model successfully replicates that the hazard function of low educated women is initially higher and falls steeply with time on the market, while the hazard function is comparatively flat for college educated women. The fit is not perfect however: the model female hazard for uneducated women is not steep enough. This could be improved by further increasing $\bar{n}$, the standard deviation of charm, but this also requires decreasing $F$ to keep the average hazard constant for types $e=0$. The trade-off for the overall fit, however, is that the female hazard for educated women is already too low, and decreasing $F$ would reduce it even further. Of course, improving the fit would be possible by introducing an additional free parameter. For example, we could allow highly educated women to have an additional payoff through matching. Given male income $y$ is empirically positively correlated with male education, a natural way would be to introduce match payoffs whereby educated women have an additional payoff by matching with educated men (see Greenwood et al. 2016).

\footnotetext{
${ }^{19}$ For the parameterised model the match rates of $\mathcal{H}$-charm women fall steeply with wages (i.e., the selection effect always dominates) while the match rates of $\mathcal{L}$-charm women are not monotonic in ability (i.e., the selection effect only dominates at sufficiently high wages).
} 


\subsection{Comparative Statics and Discussion}

Given the above parameter values, we now assess the impact of equal opportunities and advances in contraceptive technologies on female labor market and marital outcomes. We also describe their impact on female welfare by type.

\section{The Impact of Equal Opportunities: Data and Model Insights.}

There is clear empirical evidence that the removal of marriage bars in the teaching and clerical professions had a major effect on female labor supply. For example, in 1920 only one in ten of all married women in the labor force were teachers or clerical workers. By 1970 that proportion had risen to 40\% (Goldin 1991). Figure 1 describes the employment rates of all women aged 25-34 depending on their marital status and motherhood. Single (never married) women in this age group have always had relatively high labor market participation rates (around 80\% since 1940). But beginning in the early 1950s, there is a dramatic surge in the labor market participation rates of young married women, and especially those with children. Given the Goldin (1991) statistic reported above, the arrival of equal opportunities clearly led to many women with children holding on to their teaching and clerical jobs.

Given mothers could now continue in their careers, equal opportunities radically changed the female return to a college education: rather than anticipating to be in the labor market for only a few years while single and childless, young women might expect a lifelong return to investing in a qualification. Over the period 1940-2009, Figure 4 reports the fraction of women aged 25-34 with a college education and so describes the average education choice of women in the 15-24 age group made in the previous decade. With rational expectations, Figure 1 also describes female expectations of future labor market participation rates when married with children. As higher participation rates increase the return to education, more women naturally choose to invest in a costly education. Taken together, Figures 1 and 4 demonstrate the coincident increases in female education and employment following the 1950s.

The model is fully consistent with this view of the data. According to the model and prior to the arrival of equal opportunities, married women with children could only earn low wages $y$ in the labor market. With sufficiently high child care costs $\phi>y$, married women withdrew from the labor market to become homemakers. Anticipating such a future, young women had little incentive (none in the model) to invest in a costly college education and female education rates are correspondingly small (zero in the model). In 
the corresponding marriage market, male match preferences were then largely driven by female charm. For the above parameters with unequal opportunities, equilibrium matching yields (annuitized) female values $r V_{\mathcal{H}}=\$ 62,570$ and $r V_{\mathcal{L}}=\$ 23,144$ which depend on charm type $j=\mathcal{L}, \mathcal{H}$ but are independent of female ability. The charm premium, defined as $\psi \equiv r\left[V_{\mathcal{H}}-V_{\mathcal{L}}\right] / 2$, then measures the flow benefit to a single woman by having high charm $n=\bar{n}$ relative to mean charm $n=0$. Although this charm premium is substantial, $\psi=\$ 19,713$ per annum, it is substantially less than the competitive charm premium $\bar{n}=\$ 25,900$ that would be obtained in a frictionless TU framework. Instead NTU and search frictions find charming women only extract a fraction $\psi / \bar{n}=76 \%$ of the marital surplus generated by their charm, and do so by being suitably selective over potential partners rather than by receiving explicit utility transfers.

The arrival of equal opportunities directly increases the labor market participation rates of women with children, which then has a large effect on female education rates (the parameter values ensure $25.5 \%$ of women attend college). Although the large majority of women are made better off by the arrival of equal opportunities, the bottom $18 \%$ of $\mathcal{L}$-type women by ability are worse off, as are the bottom $24 \%$ of $\mathcal{H}$-types. For these women, equal opportunities in the labor market offer little benefit. They are made worse off because male marital preferences move against them: the increase in fitness across higher ability women makes men more selective in the marriage market and it becomes harder for low ability women to attract desirable male partners.

The arrival of equal opportunities also changes the value of charm to women. For the highest ability women, equal opportunities implies the charm premium becomes very small: $\psi(\bar{\alpha})=\$ 7,670 \ll \bar{n}$, a figure which is also dwarfed by the size of their earnings $(\$ 157,000$ at the very top end). The reason for this fall in the charm premium is that high wage women are already highly selective in the singles market and for them, added charm, which attracts even more male attention, is of little value. In contrast, for the lowest ability women, the charm premium increases to $\psi(\underline{\alpha})=\$ 22,776$. Charm, thus, becomes more valuable to low ability women who find it more difficult to attract desirable partners.

\section{The Impact of Improved Contraception}

According to the model and prior to the arrival of equal opportunities, women had no (or very little) incentive to invest in a college education. Given that, it follows an 
improved contraceptive technology, by itself, could not have a significant impact on female education rates. There is some empirical support for this view. As mentioned in the Introduction, a new latex technology which dramatically affected the production and usage of condoms among Americans in the 1920s and 1930s, had no significant impact on female education rates and economic activity. Going even further back in time, the invention of vulcanized rubber in 1844, which not only resulted in cheaper and more reliable condoms but also fuelled the production of diaphragms and other barrier methods, also had no effect on female economic activity (Guinnane 2011). Absent of equal opportunities it would seem unlikely that the advent of the pill, by itself, would have had a large impact on female education rates.

As discussed in Goldin and Katz (2002) and Bailey (2006 and 2010), identifying the impact of the pill on female economic behavior is difficult for its advent coincided precisely with the arrival of equal opportunities for women. The view here is that the impact of the pill is best understood as an interaction effect: given the arrival of equal opportunities, how then did the pill innovation additionally increase female education rates?

Goldin and Katz (2002) argue that improved contraception raises $u$ (the flow payoff of being single) which, by increasing female incentives to delay marriage, then encourages more single women to invest in a college education. Suppose then a contraceptive innovation increases $u$. Recall that agent $\alpha=\alpha_{j}$ with $j=\mathcal{L}, \mathcal{H}$ describes the marginal investor. As the marginal investor behaves optimally then, ceteris paribus, the Envelope Theorem implies an increase in $u$ raises her value of being single in proportion to the time she expects to remain single. The impact of increased $u$ on her return to education is therefore proportional to the difference in her expected time to marriage across those respective choices $e=\{0,1\}$.

Figure 3 describes the equilibrium hazard rates into first partnership by charm and ability for the calibrated model. The figure reveals that the switch to $e=1$ at $\alpha=\alpha_{\mathcal{L}}, \alpha_{\mathcal{H}}$ yields only a very small decrease in matching rates. The education switch to $e=1$ increases male proposal propensities (her fitness $z$ increases) which tends to increase her match rate, but the family tax means she also becomes more selective. In general the net effect is ambiguous, the calibrated model finds the net effect is small: for the marginal investor, an investment in education has only a very small impact on marriage rates. Thus for the marginal investor, an increase in $u$ has only a very small impact on her return to education. 
There are, however, additional equilibrium effects. Because improved contraception raises the flow return to being single, singles will tend to become more selective which makes members of the opposite sex worse off. This potentially increases the return to education, for education is one way by which a woman can increase her fitness and so increase male proposal propensities. For the calibrated model, therefore, Table 4 describes the comparative static of increasing $u$ (reported as dollar per week) on female education rates.

The comparative static finds an increase in $u$ has a small but negative impact on education rates among $\mathcal{L}$-charm women, and almost no effect on $\mathcal{H}$-charm women. This is not entirely surprising: it is unlikely that something which raises the value of leisure while single relative to being married, could have a large, positive impact on educational investment. Only once $u$ is extraordinarily large $(u=\$ 640$ per week) does the model find that education rates begin to increase with $u$.

For the pill to have had any effect on female education rates, its impact then must instead be through subsidising the (psychic) cost $c$ of education. Such an argument is not straightforward, however, because attending college is not a prerequisite for using the pill. Even if it is the case that the pill makes single life more fun relative to being married, it does so both for those who attend college and those who do not, and so is not necessarily an education subsidy.

One approach is to argue that, in the 1960s and early 1970s, it might have been easier (or less embarrassing) to obtain the pill from the campus doctor than from the family doctor. Furthermore, as university life typically implies spending time further away from family constraints, the advent of the pill might have made singlehood relatively more enjoyable if lived on campus. The available data are consistent with this line of argument: using a sample of women aged 18-21 in the 1973 National Survey of Family Growth (NSFG73), finds that about $50 \%$ of the women who stopped their education with high school or lower qualifications used the pill, while almost $63 \%$ of those who continued into college did so. ${ }^{20}$

An alternative argument is that women who attend college must instead defer partnership search. According to the calibrated model, a type $(\alpha, j)$ with $j \in\{\mathcal{L}, \mathcal{H}\}$ who chooses $e=0$ and immediately enters the singles market enjoys value $V_{j}(\alpha)$. Suppose

\footnotetext{
${ }^{20}$ Repeating the exercise with data from the NSFG76 leads to virtually the same results. This evidence is consistent with that presented by Goldin and Katz (2002, Figures 1 and 2).
} 
instead she chooses $e=1$ and enjoys payoff

$$
-c+\frac{u}{r}\left[1-e^{-4 r}\right]+e^{-4 r} V_{j}(\lambda \alpha)
$$

where over four years she enjoys flow $u$ while single in college but cannot search for a long term partner until after graduation. Arranging terms appropriately, the marginal investor $\alpha_{j}$ is then identified by

$$
c+\left[r V_{j}\left(\alpha_{j}\right)-u\right]\left(\frac{1-e^{-4 r}}{r}\right)=e^{-4 r}\left[V_{j}\left(\lambda \alpha_{j}\right)-V_{j}\left(\alpha_{j}\right)\right]
$$

The right hand side describes the return to education and the above discussion has established, for the marginal investor, that this return changes very little with $u$. The left hand side of (22) is the cost of education where the second term describes the opportunity cost of delayed marital search. As the flow surplus to marital search $\left[r V_{j}\left(\alpha_{j}\right)-u\right]$ decreases with $u$, it then follows that an increase in $u$ reduces the (real) cost of education. This term thus captures Goldin and Katz's (2002) notion that increasing $u$ reduces the cost of deferred marital search.

To evaluate how large such cost subsidies need to be to generate significant effects on female education rates, we consider the simpler first argument: that the gross cost of education is $\mathcal{C}=c-u^{C}\left[1-e^{-4 r}\right] / r$, where $u^{C}$ represents the added flow value to have better access to the pill while studying at college and while away from parental influence. The results of this exercise are reported in Table 5. The estimates demonstrate that relatively small subsidies (of the order of $4-5 \%$ of the total educational cost) can have large effects on college education rates. This evidence is in line with the economic literature that shows that small (parental) transfers are also likely to substantially increase college enrolment (Keane and Wolpin 2001; Cameron and Taber 2004). Thus given equal opportunities, there exist feasible mechanisms by which the contraceptive pill had an additional impact on female education rates in the 1960s and early 1970s.

\section{Conclusion}

This paper has developed a new equilibrium marriage model of two-sided search where ex-ante heterogenous individuals have general payoff functions with vectors of attributes. The approach is powerful for it identifies a simple algorithm which, in the numerical application, is found to rapidly converge to equilibrium. Using indirect inference with 
target moments including female hazard rates into first partnership by age and education choice, the empirical section identifies the different impacts of female ability and charm on female match incentives. Because the arrival of equal opportunities for women increased female wages but arguably had little impact on the value of other female attributes, the paper identifies how such opportunities had far-reaching consequences for women both in the labor and marriage markets and their associated welfare implications across heterogeneous types.

Although the focus of the application has been on the marriage market with nontransferable utility, the formal analysis also applies to a labor market context with wage bargaining. Of course a steady state equilibrium in a labor market framework not only requires solving for the matching equilibrium, as done here, but the steady state distribution of types is endogenously determined depending on the inflows and outflows of trading agents. Burdett and Coles $(1997,1999)$ show why that extended approach generates additional sorting externalities, since agent match strategies then affect the steady state composition of singles, and how such feedback effects may then generate multiple equilibria. In numerical work, updating the type distribution by solving standard steady state flow conditions is not a difficult computational problem (e.g., Greenwood et al. [2016] among many others). Of course such composition effects also arise in a marriage market context when fertility is a choice. For example, Baudin, de la Croix, and Gobbi (2015) find that more educated women are more likely to remain childless. In our framework this is consistent with a sorting explanation: educated women who anticipate not having children (i.e., they have a low family payoff $F_{i}$ ) participate more in the labor market and so have a greater return to educational investment. 


\section{Appendix}

\section{Data Sources}

Our data sources, which we use for the discussion in the Introduction and the numerical exercise in Section 3, come from the Integrated Public Use Microdata Series (IPUMS) of the decennial censuses (Ruggles et al. 2010) and the National Survey of Family Growth (NSFG).

IPUMS - We use decennial censuses from 1850 to 2000 (1890 is missing), and the 2009 American Community Survey sample, which is a $1 \%$ national random sample of the population. Detailed information on education, which is grouped in 12 different categories in the variable EDUC, is not available before the 1940 Census. Data on labor force participation come from the variable LABFORCE and cover all census years with the exception of 1850, in which the information for women is not recorded. For our analysis we select only women who are aged between 25 and 34 for the education and labor market statistics. The sample size therefore varies across censuses and outcomes. Sample sizes for Figures 1 and 4 therefore vary from about 20,000 women in 1860 to about 1 million in 2000 .

Figure 1 shows the trends in the proportion of women aged 25-34 who are in paid employment, expressed in percentage terms. Unemployed women and women who are out of the labor force in that age range are in the base category. Besides all women, the figure also shows the trends for mothers and for women who are single and never married. ${ }^{21}$ The red vertical lines are drawn in correspondence of the diffusion of birth technology improvements. That is, the 1860 line corresponds to vulcanized rubber condoms, which followed the invention of vulcanized rubber in 1844 and its application to the production of condoms in 1855 (Guinnane 2011); the 1940 line represents the 1936 legalization of contraceptive use for family planning, which followed the introduction of the latex technology in 1919; the 1965 and 1980 lines capture the diffusion of the pill, which after the introduction of Enovid in 1960 took time before a full liberalization of access to oral contraception (Goldin and Katz 2002; Bailey 2006, 2010).

Figure 4 shows the proportion of women aged 25-34 who have a university degree or higher qualification. The vertical lines are drawn in correspondence of 1940 (legalization of condom use for family planning), 1965 and 1980 (diffusion of the pill).

Finally, data on male earnings come the 2000 Census and are computed using the variable INCWAGE. The statistics reported in the text (Table 1) are calculated on all males born between 1951 and 1960 (hence aged 40-49 in 2000) after dropping the top and bottom $1 \%$ of the distribution of INCWAGE out of the analysis.

NSFG - Our analysis uses Cycles 1-7 collected by the National Center for Health Statistics in 1973, 1976, 1982, 1988, 1995, 2002, and 2006-2010. Each sample contains information on women aged 15-44.

The surveys for cycles 1-5 (up to 1995) were based on personal interviews conducted in the homes of a national sample of women in the civilian, noninstitutionalized population of the United States. The main purpose of the 1973-1995 surveys was to provide reliable national data on marriage, divorce, contraception, infertility, and the health of

\footnotetext{
${ }^{21}$ Because data on marital status are available only since the 1880 census and not before, the employment series for single, never married women can only be constructed from that year onwards.
} 
women and infants. Cycles 1 and 2 (1973 and 1976) collected information only on currently or formerly married females, so they do not allow us to construct series for single, never married women.

Cycle 6 (2002), in which both men and women were interviewed, was based on an area probability sample. The sample represents the household population of the United States, 15-44 years of age. The survey sample is designed to produce national data, not estimates for individual states. In-person interviews were completed with 7,643 female respondents (and 4,928 males). The response rate was $79 \%$ overall $-80 \%$ for females and $78 \%$ for males. Cycle 7 (2006-2010) is similar to cycle 6, except that interviews in this case were done 48 weeks of every year for 4 years, from June 2006 through June 2010. This cycle interviewed a nationally representative sample of 22,682 women and men 15-44 years of age living in households in the United States.

Each cycle contains direct information on each of the variables of interest (education, and labor force participation) in all data collection years. As in the case of IPUMS, sample sizes vary across outcomes and cycles, ranging from about 2,000 women in cycle 6 to about 4,400 women in cycle 7 . As mentioned, because cycles 1 and 2 did not sample never married women, the employment rate series in Figure 1 and the education rate series in Figure 4 for this group of women start only from cycle 3 (1982). Using the NSFG 2002-2003 cycle on all women aged 14 to 44, Figure 2 shows the distribution of the age at first partnership by education type. These statistics were obtained from life table analysis (Kalbeisch and Prentice 2002) on a total sample of more than 7,500 women.

The baseline parameters reported in Table 1 and used in the calibration analysis are standard. One note on the way we have computed the full cost of education, $c$, is in order. The source is the National Center for Education Statistics, U.S. Department of Education (http://inces.ed.gov) Digest of Education Statistics: 2013. According to this source, the average annual cost for undergraduate tuition and fees in public institutions offering a 4-year degree calculated between 2000 and 2003 is $\$ 3,967.25$ in current dollars (with values ranging from $\$ 3,501$ to $\$ 4,587$ ). The corresponding total over the 4-year period is $\$ 15,869$. (The same annual statistic including room and board is $\$ 9,575$ for a total over the 4-year period of $\$ 38,300$.) Our measure of opportunity cost is based on the Federal Minimum Wage in 2000 of $\$ 5.15$ per hour (source: U.S. Department of Labor, History of Federal Minimum Wage Rates Under the Fair Labor Standards Act, 1938 2009, http://www.dol.gov/whd/minwage/chart.htm). Assuming 2000 hours per year for a full time worker (40 weekly hours over 50 weeks in a year), total annual earning will be $\$ 10,300$, which over 4 years become $\$ 41,200$. Summing up this and the direct cost of education leads to a total of $\$ 57,069$ over four years. An alternative measure of the opportunity cost is given by the observed average earnings for women of all races, who high-school graduates (including GED) and aged 18-21. This figure is $\$ 9,042$ (s.d. = $\$ 11,076)$ from the U.S. Census 2000. Over the 4-year period, this translates to $\$ 36,168$, which summed up to the direct cost of education becomes $\$ 52,037$. We have performed the analysis using this new estimate, but all our results remain unchanged. Finally, we have also performed the analysis using the figure for the cost of education that includes room and board. This is $\$ 79,500$ over the 4-year period. Again, all the results of the paper are qualitatively unchanged. 


\section{References}

Acemoglu, Daron, David H. Autor, and David Lyle. 2004. "Women, War, and Wages: The Effect of Female Labor Supply on the Wage Structure at Midcentury." Journal of Political Economy, 112(3): 497-551.

Aiyagari, S. Rao, Jeremy Greenwood, and Nezih Guner. 2000 "On the State of the Union." Journal of Political Economy, 108(2): 213-244.

Albanesi, Stefania, and Claudia Olivetti. 2016. "Gender Roles and Medical Progress." Journal of Political Economy, 124(3): 650-695.

Bailey, Martha J. 2006. "More Power to the Pill: The Impact of Contraceptive Freedom on Women's Lifecycle Labor Supply." Quarterly Journal of Economics, 121(1): 289-320.

Bailey, Martha J. 2010. “"Momma's Got the Pill': How Anthony Comstock and Griswold v. Connecticut Shaped US Childbearing." American Economic Review, 100(1): 98-129.

Baudin, Thomas, David de la Croix, Paula E. Gobbi. 2015. "Fertility and Childlessness in the United States." American Economic Review, 105(6): 1852-1882.

Becker, Gary S. 1973. "A Theory of Marriage: Part I." Journal of Political Economy, 81(4): $813-46$.

Becker, Gary S. 1974. "A Theory of Marriage: Part II." Journal of Political Economy, 82(2, pt. 2): S11-S26.

Beller, Andrea H. 1982. "The Impact of Equal Opportunity Policy on Sex Differentials in Earnings and Occupations." American Economic Review Papers and Proceedings, 72(2): 171175 .

Bloch, Francis, and Harl Ryder. 2000. "Two Sided Search, Marriages and Matchmakers." International Economic Review 41(1): 93-115.

Browning, Martin, and Pierre-André Chiappori. 1998. "Efficient Intra-Household Allocations: A General Characterization and Empirical Tests." Econometrica, 66(6): 1241-1278.

Browning, Martin, Pierre-André Chiappori, and Yoram Weiss. 2014. Economics of the Family. Cambridge: Cambridge University Press.

Burdett, Kenneth, and Melvyn G. Coles. 1997. "Marriage and Class." Quarterly Journal of Economics, 112(1): 141-68.

Burdett, Kenneth, and Melvyn G. Coles. 1999. "Long-Term Partnership Formation: Marriage and Employment." Economic Journal, 109: F307-F334.

Burdett, Kenneth, and Melvyn G. Coles. 2001. "Transplants and Implants: The Economics of Self-Improvement." International Economic Review, 42(3): 597-616.

Burdett, Kenneth, and Randall Wright. 1998. "Two-Sided Search with Nontransferable Utility." Review of Economic Dynamics, 1(1): 220-245.

Buss, David M. 2003. The Evolution of Desire: Strategies of Human Mating. New York: Basic Books (revised edition).

Cameron Stephen V., and Christopher Taber. 2004. "Estimation of Educational Borrowing Constraints Using Returns to Schooling." Journal of Political Economy, 112(1, part 1): 132182.

Card, David. 1999. "The Causal Effect of Education on Earnings." In Handbook of Labor Economics, vol. 3, edited by Orley Ashenfelter and David Card, chapter 30, pp. 1801-1863. 
Carrillo-Tudela, Carlos, and Ludo Visschers. 2016. "Unemployment and Endogenous Reallocation over the Business Cycle." Mimeo, May.

Chade, Hector. 2001. "Two-Sided Search and Perfect Segregation with Fixed Search Costs." Mathematical Social Sciences, 42(1): 31-51.

Chade, Hector, and Gustavo Ventura 2002. "Taxes and marriage: a two sided search analysis", International Economic Review, 43(3): 955-85.

Chiappori, Pierre-André. 1992. "Collective Labor Supply and Welfare." Journal of Political Economy, 100(3): 437-467.

Chiappori, Pierre-André, Sonia Oreffice, and Climent Quintana-Domeque. 2012. "Fatter Attraction: Anthropometric and Socioeconomic Matching on the Marriage Market." Journal of Political Economy, 120(4): 659-695.

Chiappori, Pierre-André, and Yoram Weiss. 2007. "Divorce, Remarriage, and Child Support." Journal of Labor Economics, 25(1): 37-74.

Choo, Eugene, and Aloysius Siow. 2006. "Who Marries Whom and Why." Journal of Political Economy, 114(1): 175-201.

Cole, Harold L., George J. Mailath, and Andrew Postlewaite 1992. "Social Norms, Savings Behavior and Growth." Journal of Political Economy, 100(6): 1092-1125.

Coles, Melvyn G., and Marco Francesconi. 2011. "On the Emergence of Toyboys: The Timing of Marriage with Aging and Uncertain Careers." International Economic Review, 52(3): 825853.

Costa, Dora L. 2000. "From Mill Town to Board Room: The Rise of Women's Paid Labor." Journal of Economic Perspectives, 14(4): 101-122.

Díaz-Giménez, Javier, and Eugenio Giolito. 2013. "Accounting for the Timing of First Marriages." International Economic Review, 54(1): 135-158.

Doepke, Matthias, Moshe Hazan, and Yishay D. Maoz. 2014. "The Baby Boom and World War II: A Macroeconomic Analysis." Mimeo, September.

Dupuy, Arnaud, and Alfred Galichon. 2014. "Personality Traits and the Marriage Market." Journal of Political Economy, 122(6): 1271-1319.

Eckstein, Zvi, and Kenneth I. Wolpin. 1989. "Dynamic Labour Force Participation of Married Women and Endogenous Work Experience." Review of Economic Studies, 56(3): 375-390.

Eeckhout, Jan. 1999. "Bilateral Search and Vertical Heterogeneity." International Economic Review 40(4): 869-87.

Eeckhout, Jan, and Philipp Kircher. 2011. "Identifying Sorting - In Theory." Review of Economic Studies 78(3): 872-906.

Fernandez, Raquel, Alessandra Fogli, and Claudia Olivetti. 2004. "Mothers and Sons: Preference Formation and Female Labor Force Dynamics." Quarterly Journal of Economics, 119(4): 1249-1299.

Fernandez, Raquel, Nezih Guner, and John Knowles. 2005. "Female Labor Force Dynamics." Quarterly Journal of Economics, 119(4): 1249-1299.

Fisman, Raymond, Sheena S. Iyengar, Emir Kamenica, and Itamar Simonson. 2006. "Gender Differences in Mate Selection: Evidence from a Speed Dating Experiment." Quarterly Journal of Economics, 121(2): 673-697.

Gale, David, and Lloyd S. Shapley. 1962. "College Admissions and the Stability of Marriage." American Mathematical Monthly, 69(1): 9-15. 
Galichon, Alfred, and Bernard Salanié. 2010. "Matching with Trade-Offs: Revealed Preferences Over Competing Characteristics." Mimeo, March.

Gautier, Pieter A., Michael Svarer, and Coen N. Teulings. 2010. "Marriage and the City: Search Frictions and Sorting of Singles." Journal of Urban Economics 67(2): 206-218.

Goldin, Claudia. 1990. Understanding the Gender Gap: An Economic History of American Women. New York: Oxford University Press.

Goldin, Claudia. 1991. "Marriage Bars: Discrimination against Married Women Workers from the 1920s to the 1950s." In Favorites of Fortune: Technology, Growth, and Economic Development since the Industrial Revolution, edited by Patrice Higonnet, David S. Landes, and Henry Rosovsky. Cambridge, MA: Harvard University Press, pp. 511-536.

Goldin, Claudia. 2006. "The Quiet Revolution That Transformed Women's Employment, Education, and Family." American Economic Review Papers and Proceedings, 96(2): 1-21.

Goldin, Claudia, and Lawrence F. Katz. 2002. "The Power of the Pill: Oral Contraceptives and Women's Career and Marriage Decisions." Journal of Political Economy, 110(4): 730770 .

Goldin, Claudia, and Claudia Olivetti. 2013. "Shocking Labor Supply: A Reassessment of the Role of World War II on Women's Labor Supply." American Economic Review Papers and Proceedings, 103(3): 257-262.

Greenwood, Jeremy, Nezih Guner, Georgi Kocharkov, and Cezar Santos. 2016. "Technology and the Changing Family: A Unified Model of Marriage, Divorce, Educational Attainment, and Married Female Labor-Force Participation." American Economic Journal: Macroeconomics, 8(1): $1-41$.

Greenwood, Jeremy, Ananth Seshadri, and Guillaume Vandenbroucke. 2005. "The Baby Boom and Baby Bust." American Economic Review, 95(1): 183-207.

Greenwood, Jeremy, Ananth Seshadri, and Mehmet Yorukoglu. 2005. "Engines of Liberation." Review of Economic Studies, 72(1): 109-133.

Guinnane, Timothy A. 2011. "The Historical Fertility Transition." Journal of Economic Literature, 49(3): 589-614.

Hamermesh, Daniel S., and Jeff E. Biddle. 1994. "Beauty and the Labor Market." American Economic Review, 84(5): 1174-1194.

Harrison, Cynthia E. 1988. On Account of Sex: The Politics of Women's Issues, 1945-1968. Berkeley: University of California Press.

Hess, Gregory D. 2004. "Marriage and Consumption Insurance: What's Love Got to Do with It?" Journal of Political Economy, 112(2): 290-318.

Hitsch, Günther J., Ali Hortaçsu, and Dan Ariely. 2010. "Matching and Sorting in Online Dating." American Economic Review, 100(1): 130-163.

Hsieh, Chang-Tai, Erik Hurst, Charles I. Jones, and Peter J. Klenow. 2016. "The Allocation of Talent and U.S. Economic Growth." Mimeo, May.

Jacquemet, Nicolas, and Jean-Marc Robin. 2012. "Assortative Matching and Search with Labour Supply and Home Production." Mimeo, November.

Kalbfleisch, John D., and Ross L. Prentice. 2002. The Statistical Analysis of Failure Time Data. New York: Wiley.

Keane, Michael P., and Kenneth I. Wolpin. 2001. "The Effect of Parental Transfers and Borrowing Constraints on Educational Attainment." International Economic Review, 42(4): 1051-1103. 
Kessler-Harris, Alice. 1982. Out to Work: A History of Wage-Earning Women in the United States. New York: Oxford University Press.

Kessler-Harris, Alice. 2001. In Pursuit of Equity: Women, Men, and the Quest for Economic Citizenship in 20th Century America. New York: Oxford University Press.

Lindenlaub, Ilse, and Fabien Postel-Vinay. 2016. "Multidimensional Sorting Under Random Search." Mimeo, March.

Lise, Jeremy, and Jean-Marc Robin. 2014. "The Macro-dynamics of Sorting between Workers and Firms." Mimeo, December.

Lu, Xiaohua, and R. Preston McAfee. 1996. "Matching and Expectations in a Market with Heterogeneous Agents." In Advances in Applied Microeconomics, vol. 6, edited by Michael R. Baye. Greenwich, CT: JAI Press, pp. 121-156.

Lundberg, Shelly, and Robert A. Pollak. 2013. "Cohabitation and the Uneven Retreat from Marriage in the U.S., 1950-2010." IZA Discussion Paper No. 7607.

Macartney, Suzanne, and Lynda Laughlin. 2011. "Child Care Costs in the Current Population Survey's Annual Social and Economic Supplement (CPS ASEC): A Comparison to SIPP." SEHSD Working Paper Number 2011-1, U.S. Census Bureau.

Organisation for Economic Co-operation and Development. 2008. Growing Unequal? Income Distribution and Poverty in OECD Countries. OECD Publishing.

Rosen, Ruth. 2000. The World Split Open: How the Modern Women's Movement Changed America. New York: Viking.

Ruggles, Steven, J. Trent Alexander, Katie Genadek, Ronald Goeken, Matthew B. Schroeder, and Matthew Sobek. 2010. Integrated Public Use Microdata Series: Version 5.0. Minneapolis: University of Minnesota.

Shimer, Robert, and Lones Smith. 2000. "Assortative Matching and Search." Econometrica, 68(2): 343-369.

Smith, Lones. 2006. "The Marriage Model with Search Frictions." Journal of Political Economy 114(6): 1124-1144.

Stone, Lawrence. 1977. The Family, Sex and Marriage in England 1500-1800. New York: Harper and Row.

Teulings, Coen N., and Pieter A. Gautier. 2004. "The Right Man for the Job." Review of Economic Studies, 71(2): 553-580.

Tone, Andrea. 2001. Devices and Desires: A History of Contraceptives in America. New York, NY: Hill and Wang. 
Table 1: Baseline Parameters and Functional Forms

\begin{tabular}{ll}
\hline \hline$r$ & 0.04 (per year) \\
$u$ & 0 \\
$\phi$ & $\$ 10,732$ (per year) ${ }^{a}$ \\
$\beta$ & 0.51 \\
$G^{m}(y)$ & Truncated lognormal, with $\mu_{m}=\$ 10.440$ and $\sigma_{m}=\$ 0.687^{b}$ \\
{$[y, \bar{y}]$} & {$[9,608,157,192](\$ \text { per year })^{b}$} \\
$G^{f}(\alpha \mid n)$ & $G^{m}(\cdot)$ rescaled by $\gamma$ \\
$G^{f}(n \mid \alpha)$ & Symmetric binomial, with draws from $\{-\bar{n}, \bar{n}\}$ \\
$c$ & $\$ 57,069$ (over 4 years) \\
\hline \hline
\end{tabular}

${ }^{a}$ Source: Macartney and Laughlin (2011).

${ }^{b}$ Values are from the 2000 U.S. Census.

${ }^{c}$ The values are computed using information on average annual cost for undergraduate tuition and fees in public institutions from the National Center for Education Statistics, U.S. Department of Education, Digest of Education Statistics: 2013 (http://inces.ed.gov), information on the Federal Minimum Wage in 2000 from the U.S. Department of Labor, History of Federal Minimum Wage Rates Under the Fair Labor Standards Act, 19382009 (http://www.dol.gov/whd/minwage/chart.htm), and information on earnings of female high school graduates from the 2000 U.S. Census.

Table 2: Hazards to First Partnership by Education (Target and Model)

\begin{tabular}{lccccc}
\hline \hline & \multicolumn{5}{c}{ Normalized Age } \\
\cline { 2 - 6 } Hazard & 0 (peak) & 1 & 2 & 3 & 4 \\
\hline$h_{T}^{u}($ target,$e=0)$ & 0.197 & 0.154 & 0.115 & 0.102 & 0.088 \\
$\widehat{h^{u}}($ model, $e=0)$ & 0.187 & 0.164 & 0.142 & 0.121 & 0.103 \\
& & & & & \\
$h_{T}^{e}($ target,$e=1)$ & 0.163 & 0.153 & 0.149 & 0.144 & 0.143 \\
$\widehat{h^{e}}($ model, $e=1)$ & 0.145 & 0.142 & 0.138 & 0.135 & 0.131 \\
\hline \hline
\end{tabular}

Note: $h_{T}^{j}$ and $\widehat{h^{j}}$ are the model (theoretical) and the target (empirical) hazards, respectively, for $j=u, e$. 
Table 3: Calibration Results

\begin{tabular}{ll}
\hline \hline Parameter & Estimate \\
\hline$\lambda$ & 7.86 \\
$F$ & $\$ 31,000$ \\
$\sigma$ & $\$ 8,300$ \\
$\bar{n}$ & $\$ 25,900$ \\
$\gamma$ & 1.047 \\
\hline \hline
\end{tabular}

Note: All estimates are yearly values, except for $\gamma$.

Table 4: Education Choice as the Flow Payoff of Being Single Changes, by Charm Type

\begin{tabular}{lcc}
\hline \hline & \multicolumn{2}{c}{ College Education Rate } \\
\cline { 2 - 3 }$(\$$ per week $)$ & $\mathcal{L}$-Types & $\mathcal{H}$-Types \\
\hline 0 & 0.294 & 0.217 \\
20 & 0.292 & 0.217 \\
40 & 0.290 & 0.218 \\
80 & 0.280 & 0.218 \\
160 & 0.263 & 0.219 \\
320 & 0.263 & 0.227 \\
640 & 0.277 & 0.238 \\
\hline \hline
\end{tabular}

Note: The flow payoff of being single, $u$, is expressed in dollars per week.

Table 5: Educational Investment by Charm Type

\begin{tabular}{cccc}
\hline \hline \multirow{2}{*}{$\begin{array}{c}\text { Education Cost } \\
(\$ \text { per year })\end{array}$} & $\begin{array}{c}\text { Net Subsidy, } u^{C} \\
(\$ \text { per week })\end{array}$ & \multicolumn{2}{c}{ College Education Rate } \\
\cline { 3 - 4 } 41,200 & 0 & 0.277 & 0.233 \\
43,280 & -10 & 0.211 & 0.211 \\
45,360 & -20 & 0.171 & 0.191 \\
47,440 & -30 & 0.150 & 0.172 \\
49,520 & -40 & 0.130 & 0.161 \\
\hline \hline
\end{tabular}

Note: University education and costs are assumed to be spread over 52 weeks $\times 4$ years. 
Figure 1: Female Employment Rate, Women aged 25-34

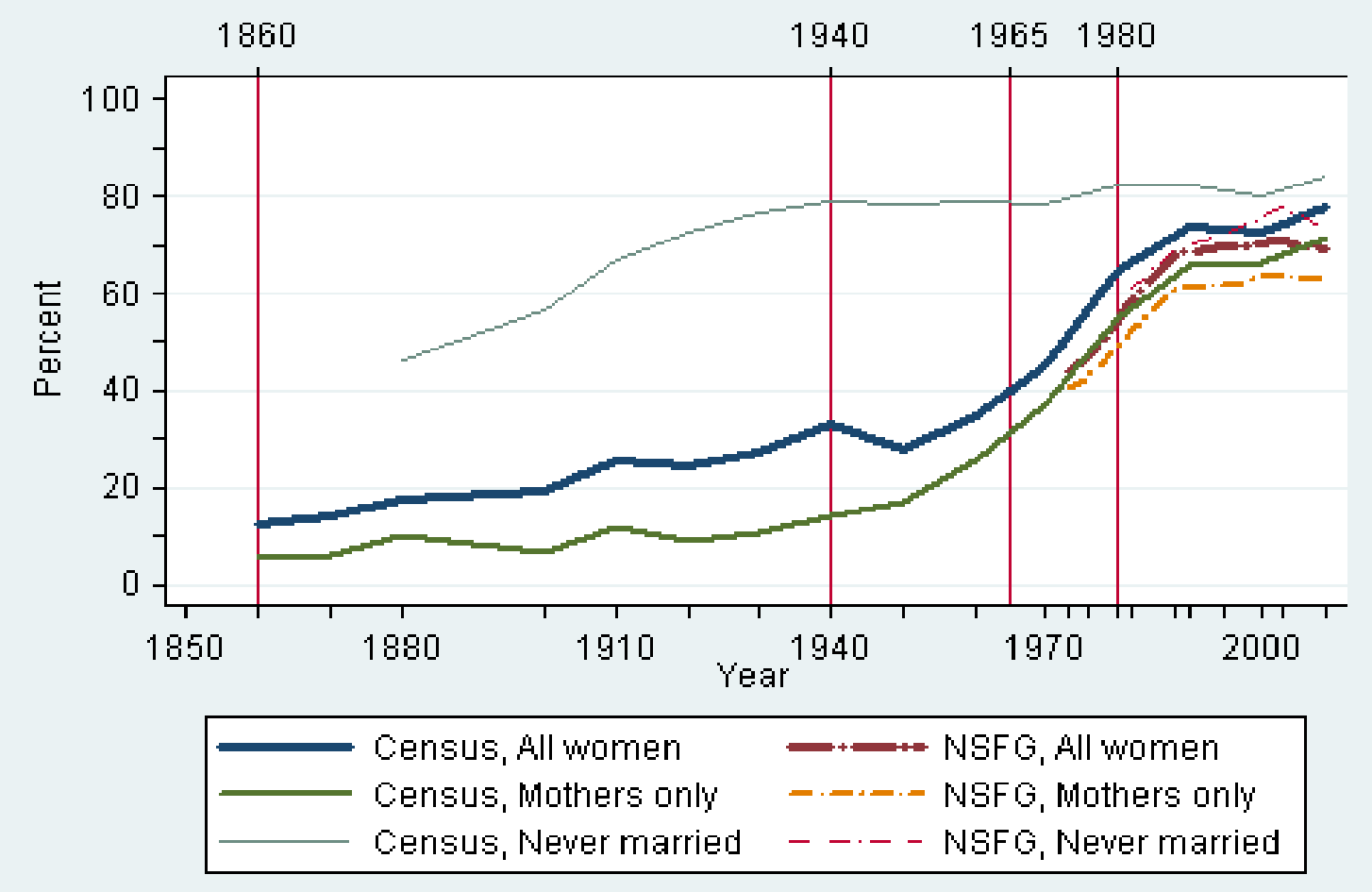

Sources: IPUMS Census 1860-2000, 2009 ACS sample; NSFG, Cycles 1-7.

Note: The vertical lines indicate the birth cohorts of women who had greater exposure to birth technology improvements. See the Data Appendix for a description of the data and variables used. 
Figure 2: Observed Female Hazards to First Partnership by Education

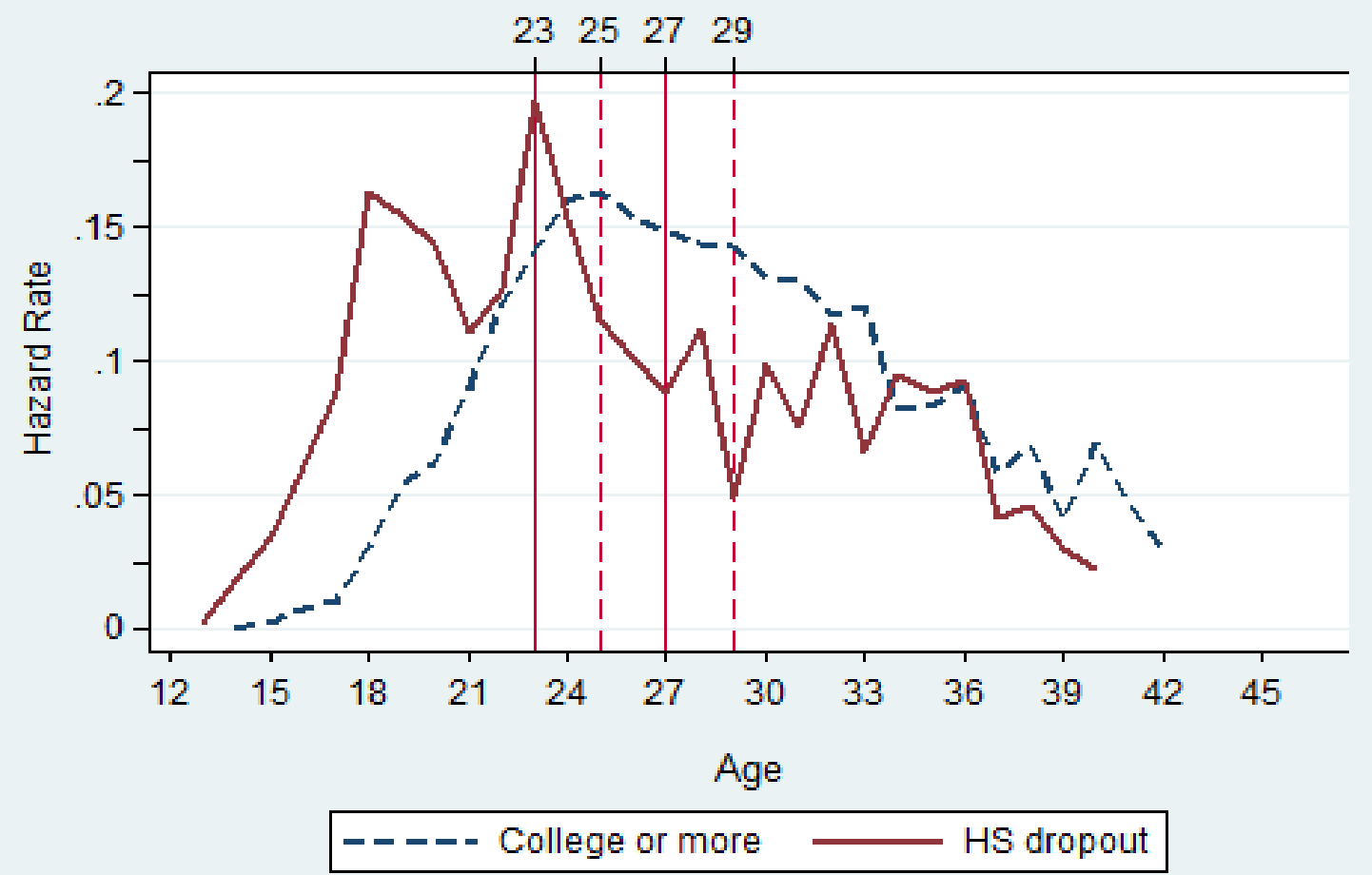

Source: NSFG 2002-2003, all women aged 14-44.

Note: The vertical lines are drawn at the age where the hazard functions peak and four years later for college educated women (solid line) and high-school dropouts (dashed line). 
Figure 3: Female Hazards to First Partnership by Ability and Charm Type

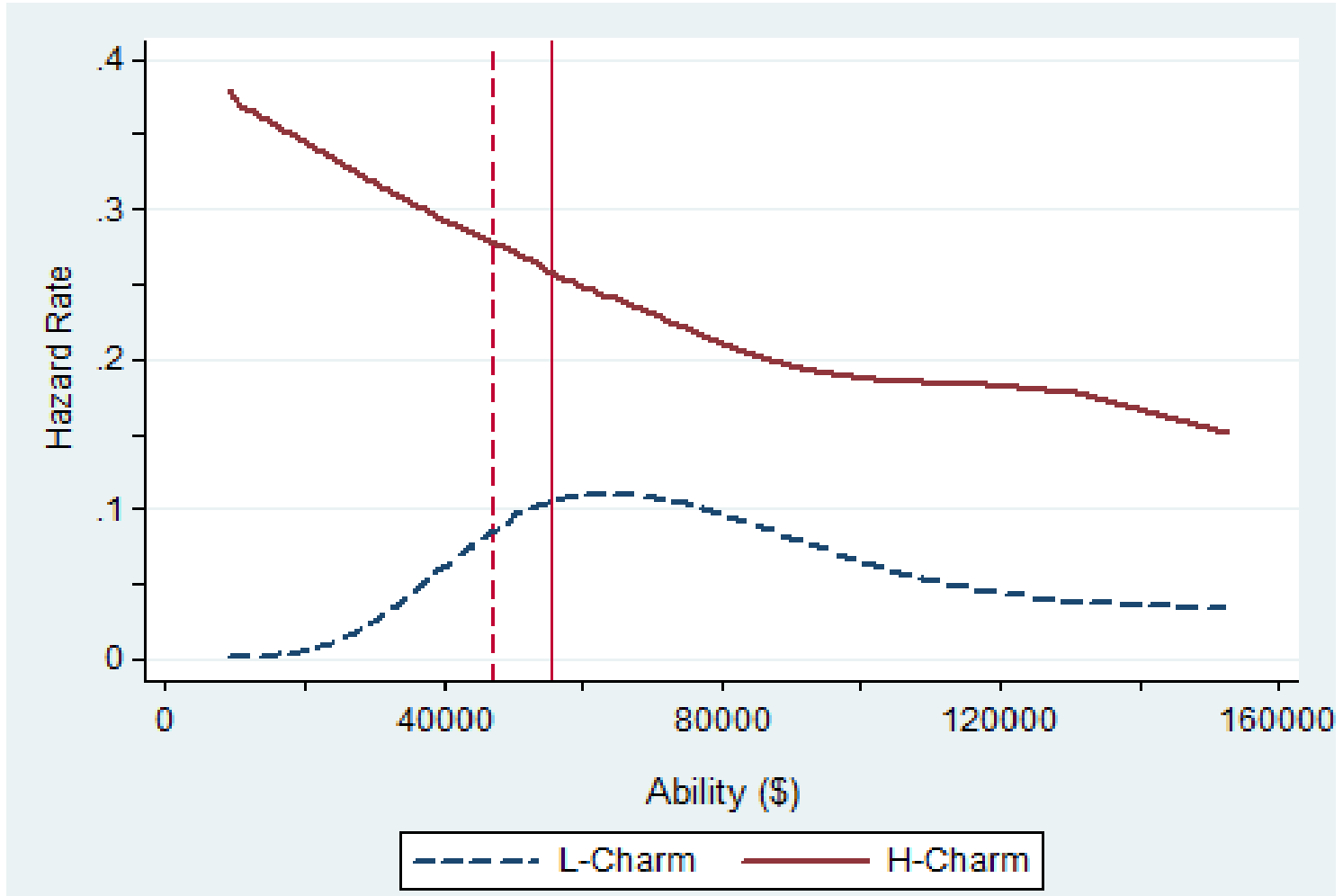

Note: The solid vertical line marks the ability threshold for $\mathcal{H}$-charm women, $\alpha_{\mathcal{H}}=\$ 55$, 400, while the dashed vertical line marks the ability threshold for $\mathcal{L}$-charm women, $\alpha_{\mathcal{L}}=\$ 47,200$. 
Figure 4: Fraction of Female College Graduates, Women aged 25-34

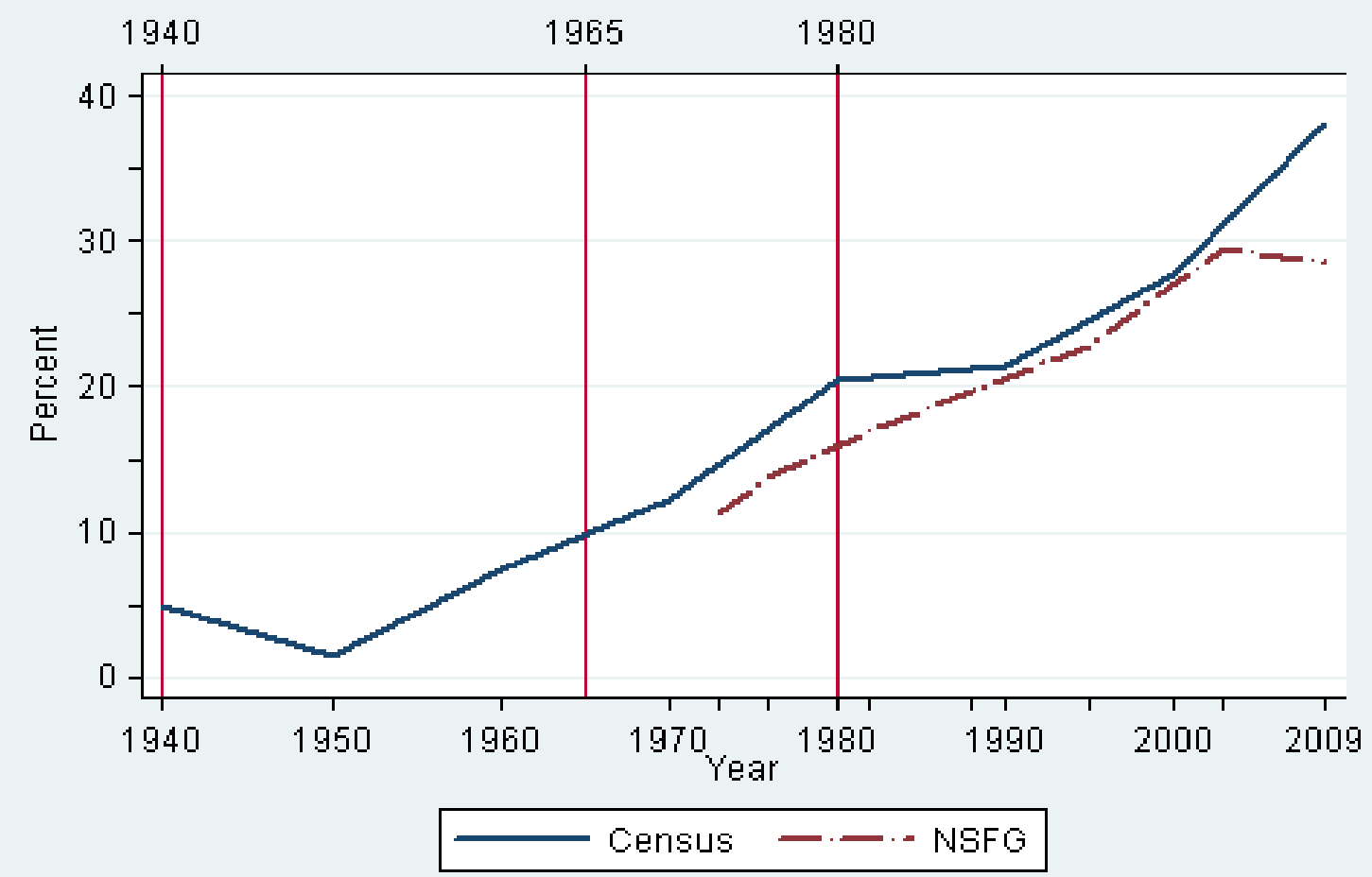

Note: See sources and note to Figure 1. 